\title{
Band electrodes in sensing applications: response characteristics and band fabrication methods
}

Danlei Li, Christopher Batchelor-McAuley, Lifu Chen, Richard G. Compton*

Department of Chemistry, Physical and Theoretical Chemistry Laboratory, University of Oxford, South Parks Road, Oxford OX1 3QZ, United Kingdom

${ }^{*}$ Corresponding author:

Email: Richard Compton richard.compton@chem.ox.ac.uk

Phone: +44(0) 1865275957

Fax: $+44(0) 1865275410$

Key words: microband electrodes; microband arrays; band fabrication; biosensors; chemical sensors; voltammetric response; high signal-to-noise ratio; low detection limits

\section{Abstract}

This review surveys the fabrication methods reported for both single microband electrodes and microband electrode arrays and their uses in sensing applications. A theoretical section on band electrodes provides background information on the structure of band electrodes, their diffusional profiles and the types of voltammetric behaviour observed. A short section summarises the currently available commercial microband electrodes. A section describing recent (10 years) sensing applications using band electrode is also presented. 
Microelectrodes have, since the 1980s, attracted a lot of attention, providing new possibilities in both fundamental studies and applications, but most notably in sensors. The International Union of Pure and Applied Chemistry (IUPAC) has defined that a microelectrode has dimensions of tens of micrometers or less, down to the submicrometer range[1] whereas other terms, for example, ultramicroelectrodes and nanoelectrodes, are sometimes used in the literature to describe electrodes with dimensions less micrometer scale. A number of advantages can be achieved by decreasing the size of an electrode to the micro- or sub-micro scale which meanwhile changes the voltammetric behaviour. Decreasing the size of an electrode to the micron or sub-micron scale alters the voltammetric behaviour offering a number of advantageous properties over conventional macroelectrodes.[1-4] First, higher current densities are obtained due to the enhanced masstransport.[2,5] Second, ohmic resistance effects decrease due to the smaller electrode size.[2,5] Third, microelectrodes have smaller capacitances which increases the signal-to-background ratio and improves the response time of the system. Furthermore, due to their size they can be applied in the measurements with samples with small volumes in, for example, medical and biological research.[6,7] Although the advantages of microelectrodes are clearly apparent, one drawback of the use of a single micro- or nano-disc electrode is the low absolute current output; the measured currents are often in the nano to sub-nanoampere range. Consequently, as a result the current measurement is sensitive to issues of electrical noise, often necessitating the use of a Faraday cage. This requirement for electrical shielding can negatively impact their application in real world sensing devices. Micro- or nanoelectrodes with a band geometry, where the electrical interface are micro- or nanoscopic in one dimension and macroscopic in the other, can address this problem of sensitivity to electrical noise; a larger current output can be produced by simply having a longer band. In addition, the total current output can also be increased by using multiple single bands operated in parallel. These so-called band arrays can offer the same sensitivity as a single band electrode but with added benefits including higher total current output and less susceptibility to interference.

Micro- to nanoband electrodes and their arrays have been fabricated as chemical sensors[8-12] or biosensors[13-22]. Sensors are widely used in various fields for example in food processing, medical fields, environmental field, where some of criteria need to be taken into consideration for the sensor design and fabrication: 1) high sensitivity and selectivity; 2) low limit of detection (LOD); 3 ) ease of fabrication.[23] The first two requirements can be realised due to the above mentioned advantages of microbands (arrays), leading to an improved signal-to-noise ratio and hence improved sensitivity and lower detection limit. Additionally microband arrays own the advantages of easy fabrication compared to microelectrode arrays with other geometries and hence provide more possibilities in applications. Important examples of the use of band electrodes for analytical applications include; the 
development of a chemical sensor based on screen printed carbon microband electrodes requiring no further chemical modification to give a low detection limit for the determination of $\mathrm{Pb}^{2+}$.[10] $\mathrm{A}$ borondoped diamond band electrode for use in end-column amperometric detection with enhanced sensitivity and lower noise level for several groups of important analytes (e.g. nitroaromatic explosives, phenols) on capillary electrophoresis microchips has been reported.[24] More recently, a capacitive biosensor with a high sensitivity and a wide dynamic detection range was fabricated using a commercialised gold interdigitated electrode array the surface of which was functionalised with 24nucleotide DNA probes to detect DNA molecules.[25]

Beyond being of analytical value band electrodes are also of importance in fundamental research. The decreased resistance and capacitance of such electrode designs offer the possibility of investigating fast electrochemical reaction mechanisms and exploring electrochemical reactions in organic solvents with low permittivity such as toluene.[26,27] Another recent example of fundamental work is that by F. Zhang et al. who reported the use of gold nanoband electrodes to study the motion of silver nanoparticles.[28] X. Li et al. measured the resistance across individual carbon nanotubes in contact with and bridging across an interdigitated gold band electrode array.[29] These wide and varied uses of micro- or nano-band electrodes encourage the investigation of reproducible fabrication methods for making thinner band electrodes or electrodes made of different materials. This review starts with a theoretical section to give an overview of the structures and the diffusional behaviour at both single microbands and microband arrays, followed by the summary of up-to-date fabrication methods for band electrodes. These two sections are presented to provide an in-depth understanding of band electrodes, which is the basis of the applications utilising such electrodes. A section summarising the currently available commercially microband electrodes known to the authors comes afterwards. Finally a section summarises research after 2010 on sensing applications using microband electrodes.

\section{Background Theory}

For a molecule freely diffusing in solutions the mean squared distanced travelled $\left\langle X^{2}\right\rangle$ in a time $t$ can be expressed by the following equation (Equation 1):

$<X^{2}>=2 D t$

where $\mathrm{D}$ is the diffusion coefficient of the species. For a molecular species in aqueous solution at 25 ${ }^{\circ} \mathrm{C}$ the diffusion coefficient is often in the range of $0.1-10 \times 10^{-9} \mathrm{~m}^{2} \mathrm{~s}^{-1}$, moreover most dynamic electrochemical experiments last between one and a few tens of seconds. Consequently, during the course of most voltammetric measurements the molecules in solution will have travelled on average between 10-1000 microns. This average distance travelled relative to the size of the electrode is 
important in determining the diffusion profile to an interface. When $\left\langle X^{2}\right\rangle^{0.5}$ is small compared to the length scale of the electrode, the mass-transport to the interface is linear. Conversely when $\left\langle X^{2}\right\rangle^{0.5}$ is large compared to the electrode length scale the mass-transport to the interface is convergent. The operative mass-transport regime controls the voltammetric response of the solution phase species at an electrode.

Chronoamperometry and cyclic voltammetry are two widely used techniques in electroanalysis. During the course of the experiment the characteristic distance travelled by a molecule varies as a function of time, as described by Equation 1. Hence, during the course of the chronoamperogram the diffusion profile will evolve; consequently, as with the current response at other electrode geometries, there is no simple expression for describing the variation of the mass-transport limited current as a function of time. Although there is no exact mathematically analytical expression for the chronoamperometric response of a single microband, the most commonly used result describing the chronoamperometric response for this band electrode geometry for a simple one electron oxidation or reduction, $A \pm \mathrm{e} \rightarrow \mathrm{B}$, under diffusion limited control is shown in Equation 2[30] with the error of up to $1.3 \%$ over the entire time range.

$$
\begin{aligned}
\frac{I(t)}{n F C D l} & =\frac{1}{\sqrt{\pi \tau}}+1, \quad \tau<\frac{2}{5} \\
& =\frac{\pi e^{-2 \sqrt{\pi \tau} / 5}}{4 \sqrt{\pi \tau}}+\frac{\pi}{\ln \left[\left(64 e^{-\gamma} \tau\right)^{1 / 2}+e^{5 / 3}\right]}, \quad \tau>\frac{2}{5}
\end{aligned}
$$

where $\mathrm{n}$ is the number of electrons transferred, $\mathrm{F}$ is the Faraday constant, $\mathrm{c}$ is the bulk concentration of the reactant, $D$ is the diffusion coefficient of the reactant, $I$ is the length of the electrode, $w$ is the width of the band electrode, $t$ is the time, $\gamma=0.5772156$ and $\tau=D t / w^{2}$. At very short times $(\tau<<2 / 5)$, the diffusion layer is small compared to the electrode dimensions and the diffusion is linear so the current follows the Cottrell equation; at very long times ( $\tau>>2 / 5)$, it is found that the amperometric current response is equivalent to a hemicylinder electrode with a radius of $w / 4 .[30]$

In terms of cyclic voltammetry, microdisc electrodes, except at fast scan rates, exhibit a sigmoidal voltammetric waveshape response with a limiting steady-state current at high overpotentials.[31] The enhanced mass transport from radial diffusion results in higher flux densities at microelectrodes as compared to the macroscopic counterparts. In contrast, unlike microdisc or microspherical electrodes, the mass transport at a band electrode, where one of the dimensions is macrocopic, is less efficient! Voltammetrically this leads to a quasi-steady-state rather than a true steady-state regime. Consequently, for a band electrodes the voltammetric response still shows a vestigial peak and at high overpotentials where diffusion control operates the current varies with the inverse of log of the 
exerimental time.[32] In the limit where the width of the band is microscopic in dimensions, the magnitude of the voltammetric response is relatively insensitive to the width of the band. Here the voltammetric peak current is approximately proportional to the length of the electrode and the electrode width to the power of 0.15 .[33] This relative insensitivity to the electrode width is shown in Figure 1, where the current only increases by a factor of $\sim 1.3$ as the band width increases by a factor of 8 . The inlay in Figure 1 shows the linear relationship between the logarithm of peak current and the logarithm of the band width with a gradient close to 0.15 [33].

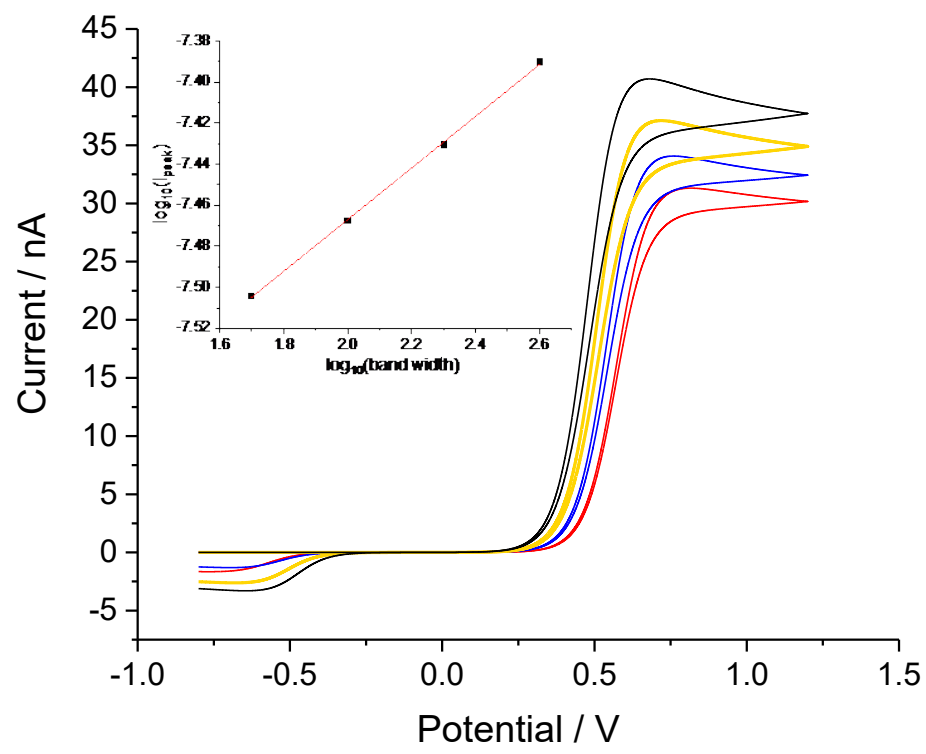

Figure 1 Simulated voltammograms on single band electrodes with various band widths: $\mathbf{w}=50 \mathrm{~nm}(\mathrm{red}), \mathbf{w}=100 \mathrm{~nm}$ (blue), w = $200 \mathrm{~nm}$ (yellow) and w = $400 \mathrm{~nm}$ (black). Parameters used in the simulations: $\mathrm{D}=1 \times 10^{-9} \mathrm{~m}^{2} \mathrm{~s}^{-1}, \mathrm{k}^{0}=1 \times 10^{-7} \mathrm{~m}$ $\mathrm{s}^{-1}, \mathrm{E}_{\mathrm{f}}=0 \mathrm{~V}, \mathrm{c}_{\text {bulk }}=1 \mathrm{mM}, \alpha=\beta=0.5$, length $=0.1 \mathrm{~cm}$. The inlay shows the plot of the logarithm of the peak current as a function of the logarithm of band width. The linear relationship gives a gradient of 0.13.

A band array comprises of multiple single bands which are positioned in parallel as schematically shown in Figure 2(a). The bands are microscopic in the $x$-direction (band width) but macroscopic in $y$ direction (length).[34] The inter-band separation is the distance between the centres of two adjacent bands in the $x$-direction. When multiple band electrodes are packed in parallel, unlike the diffusion profile at a single band, the diffusion fields from adjacent bands may interfere and compete with each other. The situation can be summarised into four diffusional categories as defined by T. J. Davies et al.[4] which are shown in Figure 2(b)[35] and the corresponding voltammograms, at the fully irreversible limit, are shown in Figure 3. These voltammograms were simulated using a home-written microband programme where the diffusional regime is operative depends on a number of factors including, the band width $w$, the inter-band separation $\delta_{\text {inter-band }}$ the molecular species diffusion coefficient $D$ and the experimental time $t$ (as often controlled by the voltammetric scan rate).[36] In category 1 which corresponds to very short times, the diffusion layer thickness is much smaller 
compared to the band width and band separation and the mass transport is dominated by linear diffusion. Here the magnitude of the voltammetric response is proportional to the total band area. In category 2 corresponds to longer times, the diffusion to each band is convergent and due to the large band separation, each band behaves independently. The measured total current equals to the collection of all isolated bands, where as discussed previously the magnitude of the voltammetric response is relatively insensitive to the electrode width. As is shown in Figure 3, the voltammetric behaviour on a band array with a band width of $100 \mathrm{~nm}$ and an inter-band separation $\delta_{\text {inter-band }}$ of 300 $\mu \mathrm{m}$ (black curve) is equivalent to that on a single microband electrode (grey curve) with a band width of $100 \mathrm{~nm}$ at a scan rate of $0.025 \mathrm{~V} \mathrm{~s}^{-1}$. However, if the inter-band separation is smaller the bands no longer remain diffusionally independent. Category 4 is the extreme of this case where the diffusion profiles overlap so significantly that the diffusional profile to the whole array becomes linear (red curve in Figure 3 with $\delta_{\text {inter-band }}$ of $0.3 \mu \mathrm{m}$ ) where the diffusion fields completely overlap leading to a linear concentration profile towards the entire array as a whole. The array then behaves the same as a macroelectrode with the same geometric area as the entire array. Obviously this destroys some of the benefits of using microelectrodes. Category 3 represents a transition between categories 2 and 4 , where the diffusion fields overlap partially between adjacent bands, which reduces the flux at the edge of the electrodes. The examples of this case is shown as green and blue curves in Figure 3 where the inter-band separation $\delta_{\text {inter-band }}$ are $30 \mu \mathrm{m}$ and $3 \mu \mathrm{m}$, respectively. Consequently, the highest sensitivity at a microband array (i.e. the average current measured per band) can only be obtained in category 2 due to the rapid diffusion at the band edge. The schematic shown in Figure 2 focuses on regular spaced band arrays[34], whilst the voltammetric responses at randomly distributed microband arrays have been studied by I. Streeter et al.[35] 
(a)

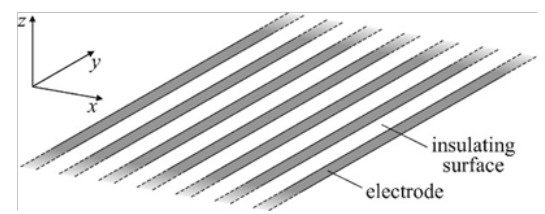

(b)

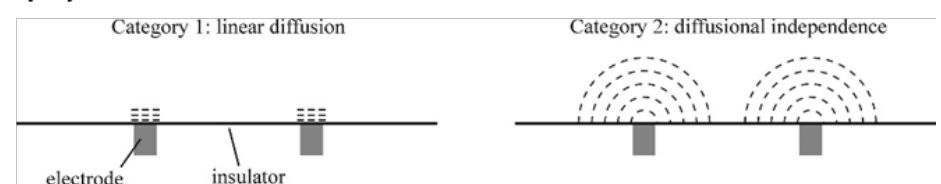

Category 3: overbping diffisionatones

Category 4: linear diffusion
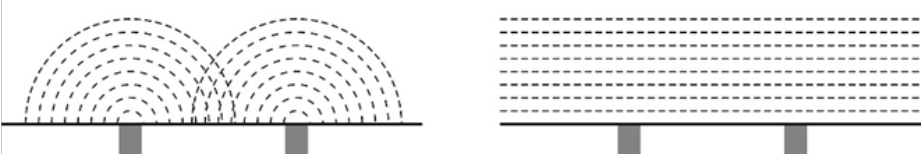

Figure 2 (a) Schematic diagram of a section of a microband array. The theoretical array extends to infinity in both $x$ - and z-directions.[34] (b) Schematic diagrams of diffusion categories 1-4 at a microband array.[35] Adapted with permission from refs. [34] and [35]. Copyright @ 2007 American Chemical Society.

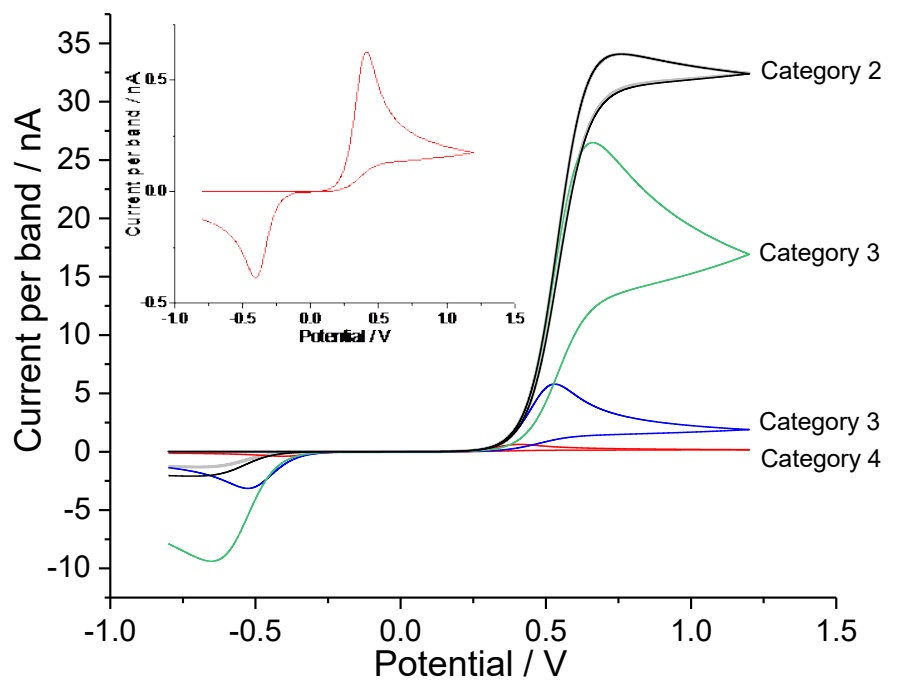

Figure 3 Simulated voltammograms on a single microband (grey) and microband arrays with variable inter-band separation ( $\delta_{\text {inter-band }}$ ) at the fully irreversible limit: $\delta_{\text {inter-band }}=0.3 \mu \mathrm{m}$ (red), $3 \mu \mathrm{m}$ (blue), $30 \mu \mathrm{m}$ (green) and $300 \mu \mathrm{m}$ (black). Inlay presents the zoom-in version of the voltammogram on the band electrode with the $\delta_{\text {inter-band }}$ of $0.3 \mu \mathrm{m}$ (red). Parameters used in the simulations: band width $=100 \mathrm{~nm}, \mathrm{D}=1 \times 10^{-9} \mathrm{~m}^{2} \mathrm{~s}^{-1}, \mathrm{k}^{0}=1 \times 10^{-7} \mathrm{~m} \mathrm{~s}^{-1}, \mathrm{E}_{\mathrm{f}}=0 \mathrm{~V}, \mathrm{c}_{\mathrm{bulk}}=1 \mathrm{mM}, \alpha=$ $\beta=0.5$, length $=0.1 \mathrm{~cm}$.

Beyond the simple band array electrodes described above another important category of electrode arrays is the so-called interdigitated electrode array. The structure of interdigitated electrode array is shown in Figure 4[37]. This configuration of the electrode consisting of two arrays that are interlaced, and if a bi-potentiostat is used the potential on each set of electrodes can be different[38-40]. These 
electrode arrays are important in generator-collector systems[41-44]. The generator electrode is used to oxidise or reduce the electroactive species and the produced species is transported via diffusion or forced convection to the collector electrode.[45] The collector electrode is held at a potential sufficient to electrochemically convert the produced species to another species.[45] The close interspacing between electrodes results in the overlap of diffusion layer across the generator and collector band electrodes, where the species formed on generator electrode can be quickly transported to collector electrode. The feedback redox loop formed can enhance the current measured at the generator electrode, giving improved sensitivity. The examples of interdigitated electrode arrays and generator-collector systems will be discussed in detail below.

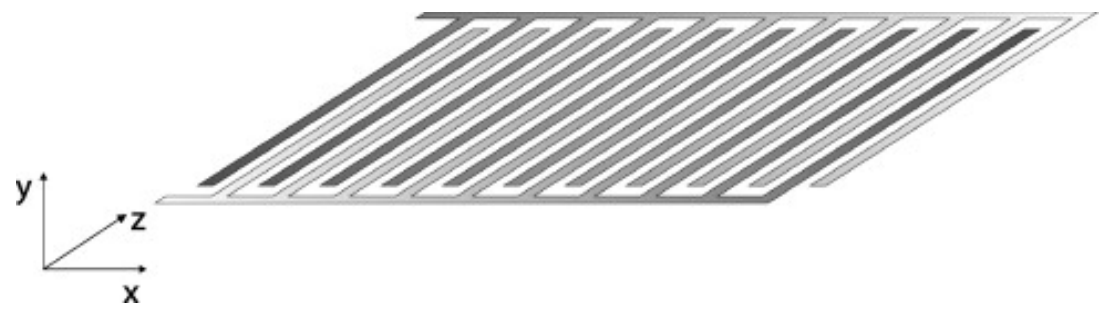

Figure 4 Schematic of interdigitated electrode arrays. Adapted with permission from ref [37]. Copyright @ 2015 Elsevier.

\section{Fabrication of Single Band Electrodes}

Generally single band electrodes are fabricated in a "sandwich" configuration, where a sheet of an electrode material is sandwiched between two insulating layers and the stack cut in a direction perpendicular to the sheet, exposing a band of the electrode material. The electrode materials are first deposited onto the insulating substrate using various methods, which, for example, include sputtering[5] or thermal vapour evaporation[5,24,46]. A second insulating layer is then either mechanically covered or surface printed (e.g. screen printing $[10,11,47]$ or photolithography[48,49]) on top of the band layer. The following two subsections are divided into "mechanical fabrication" and "surface printed fabrication" in terms of the deposition method of the insulating layers. Metals, especially gold and platinum, are the most commonly used materials to construct band electrodes because of the relatively wide commercial availability as thin sheets or foils of high purity.[50] Moreover, thin metal films can be obtained by sputtering or evaporation, which are usually applied during lithographic fabrication methods. Other materials such as graphite, carbon nanotubes (CNTs) and doped diamond have been also used as electrode materials. Table 1 gives the summary of the electrode materials, insulators and sealants used in the literature for sandwich-type band electrodes. 
Table 1 Summary of electrode materials, insulators and sealants used in the mechanical fabrication of sandwich-type band electrode.

\begin{tabular}{|l|l|l|}
\hline Electrode materials & Insulators & Sealants \\
\hline Metals (Au, Pt) & $\begin{array}{l}\text { Soft glass[51]; } \\
\text { microscope glass slide[5,43,52,53]; } \\
\text { silanized glass slides[43,54]; } \\
\text { Mylar sheet[5,55]; }\end{array}$ & $\begin{array}{l}\text { epoxy[5,9,46,54,55,58,76,77]; } \\
\text { Tefzel film[52,76]; }\end{array}$ \\
& $\begin{array}{l}\text { Tefzel film[52]; } \\
\text { laminating foil[56]; } \\
\text { cleaved muscovite mica[46,57]; } \\
\text { epoxy[9,53,54,58]; } \\
\text { Polyester film (Melinex)[57,59]; } \\
\text { Silicon nitride[16,44,48,60-75] }\end{array}$ & \\
\hline Graphite & $\begin{array}{l}\text { Heat-bondable plastic (Tefzel)[51]; } \\
\text { microscope glass slides[5]; }\end{array}$ & epoxy[5] \\
\hline Carbon nanotube & $\begin{array}{l}\text { PTFE sheet[78] } \\
\text { sheet }\end{array}$ & $\begin{array}{l}\text { Ceramic plate[24]; } \\
\text { Teflon[79] }\end{array}$ \\
\hline Boron-doped diamond & $\begin{array}{l}\text { Epoxy[24]; } \\
\text { silicon rubber[79] }\end{array}$ \\
\hline
\end{tabular}

\section{Mechanical fabrication method for single bands}

The approach to this type of electrode is relatively simple and involves the mechanical sealing of a band layer between insulating layers which are normally commercially available, for example, microscope glass slides[5,43,52], Mylar sheets[5] etc. The resulting electrodes are exposed by polishing or cutting one edge of the electrode.

Single Pt microband electrodes with thicknesses of 5-20 $\mu \mathrm{m}$ were first constructed using the sandwich method by R. M. Wightman and co-workers where the platinum band was fabricated by sealing a thin platinum sheet in soft glass with a flame and one of the edge was exposed by polishing.[51] Electrical contact was achieved using silver epoxy with a conductive metal wire. The approximate thicknesses of Pt band electrodes were determined via the use of an optical microscopy.[51] L. Xiong et al. constructed a disposable Pt band with a thickness of $50 \mu \mathrm{m}$ using thermal lamination of a piece of platinum foil and the electrical connection was established by using a piece of copper foil with a 
conductive adhesive.[56] The band electrode was exposed by cutting the lamination normal to the foil.[56]

Apart from using commercially available metal sheets as the "filling" of the sandwich, metal nanoscopic band electrodes have also been fabricated using vapour deposition or sputtering on different substrates with the thickness of the metal film controlled by the deposition time. For example, gold and platinum nanoband electrodes with thicknesses of lower to $30 \mathrm{~nm}$ were fabricated by sputtering metal film onto a glass microscope slide, which was covered with another glass slide.[5] H. S. White and co-workers successfully made sub-nanoband electrodes (thicknesses 200-500 A) which were fabricated by thermal evaporating a metal film onto a cleaved muscovite mica.[46] A gold band electrode with a thickness of $10 \mathrm{~nm}$ using similar method but depositing gold film onto a silanised microscope slide was fabricated by S. L. Caston et al. [54] B. J. Seddon et al. made a gold band electrode (thickness 7-100 nm) in which a thin gold film was vacuum evaporated onto clean polymer sheet.[59] Additionally, recordable CDs have been found to be a convenient and easily obtainable source for making thin gold band electrodes. Since the recordable compact disk consists of a polycarbonate base, a dye-photosensitive layer, a nanometric metal layer $(500-100 \mathrm{~nm})$ and one or two layers of polymeric films, sandwich-type nanoband electrodes can be obtained by first removing the protective layer to expose the gold layer which is then covered with an insulating material on the central region of the CD slide.[59] A fabrication method called "nanoskiving", a combination of thin-film deposition with a microtome, has been applied to make band electrodes as shown in Figure 5 where a gold thin film was deposited onto epoxy by sputtering, which was then embedded in epoxy to form an epoxy block and the gold band electrode was obtained by using a ultra-microtome.[9,58] In this case, the width of the band can be controlled by the thickness of sputtered Au film.[9]. Oomen et al. fabricated a electrochemical microfluidic device based on a single nanoskived gold nanowire, providing superior current response.[80] O'Riordan and his co-workers used this method to fabricate single gold nanowire, the resulting device was able to direct reduce hydrogen peroxide across $110 \mathrm{pM}$ to $1 \mathrm{mM}$ without the need of chemical modification.[81] 


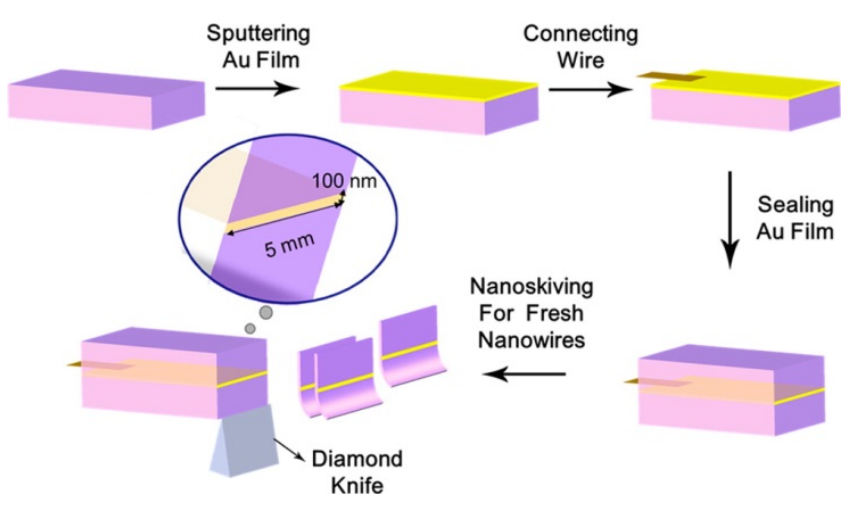

Figure 5 Schematic illustration of the procedures of nanoskiving fabrication of Au ultra-long nanowire electrode. Adapted with permission from Ref. [9]. Copyright @ 2016 American Chemical Society.

Carbon-based materials, such as graphite[5,11,51] and CNTs[78] have been fabricated into band electrodes. A graphite microband electrode was fabricated by sealing a thin sheet of graphite from the basal plane of a block of pressure-annealed pyrolytic graphite between two layers of heatbondable plastic at $260{ }^{\circ} \mathrm{C}$ for $18 \mathrm{mins}$.[51] The direct measurement of the band width was attempted but the electron micrographs of graphite band electrode showed that parts of graphite surface were occluded by the plastic bonding material and hence the accurate measurement of band was considered impossible.[51] Another sandwich-type carbon nanoband electrode was made in R. M. Wightman's group where a commercial large glass slide $(2.5 \times 7.5 \mathrm{~cm})$ coated with a $30 \mathrm{~nm}$ carbon film was cut into small pieces which were then sealed with other glass slides.[5] CNTs are cylinders of one or more layers of graphene. R. Lin et al. has recently published work on the fabrication of CNT band electrodes (thickness $191.3 \pm 47.9 \mathrm{~nm}$ ) for electrochemical sensors.[78] The CNT sheets used were drawn from CNT arrays which were grown on top of a $\mathrm{Si} / \mathrm{SiO}_{2}$ substrate using thermal chemical vapour deposition.[82] Two polytetrafluoroethylene (PTFE) plates were applied on both side of CNT sheet with epoxy. After curing, the epoxy-CNT sheet was obtained by removing the PTFE plates and then placed vertically in an epoxy resin to make a CNT-epoxy cylinder. The cured CNT-epoxy cylinder was cut into small slides and each band electrode was exposed by polishing.[78]

Turning to other materials, doped diamond has attracted much attention due to its wide potential window, low sensitivity to oxygen and stable background current. A boron-doped diamond (BDD) band electrode was fabricated by J. Wang et al. in 2003.[24] This was coupled with a micromachined capillary electrophoresis system as an end-column electrochemical detector.[24] In this work, a piece of chemically vapour deposited BDD film (thickness $40 \mu \mathrm{m}$ ) was sealed between two layers of nonconducting epoxy and the electrical contact was achieved using a copper wire with conductive epoxy.[24] Recently, P. U. Prayikaputri et al. fabricated a microband BDD electrode by a lamination 
method through sealing a piece of BDD film between two insulting plates to form a 'Teflon-Si-BDD-SiTeflon' sandwich, which was used as an adenosine phosphate sensor.[79]

\section{Surface printed fabrication method for single bands}

In this section, the band electrodes fabricated also have the 'sandwich' configuration but all layers are deposited using screen printing techniques. This allows scale up of the fabrication process. Screen printed band electrodes normally have working, reference and counter electrodes together on the surface. The fabrication of single screen printed carbon microband electrodes has been reported by D. E. Williams and co-workers[83,84]. Here a line of a suitable commercial conductive ink (Pt, Au, C etc.) was printed $2-8 \mathrm{~mm}$ wide and $\sim 10 \mu \mathrm{m}$ thick onto the surface of alumina tiles, followed by another coating layer of dielectric material.[83] The corresponding platinum, gold and carbon band electrode was obtained by cutting perpendicularly to the direction of the line and a fresh surface could be obtained by snapping along a pre-scribed line.[83] A method for fabricating disposable screen-printed ultramicroband electrodes (SPUMEs) with a width of $20 \mu \mathrm{m}$ using layer-by-layer assembly was developed by J. Chang et al. using the edge of carbon-/metal-sandwiched films between insulating layers as a band type ultramicroelectrode.[47] The fabrication procedure is shown in Figure 6(A) where the multiple-layer screen printed electrode was built using a semi-automatic screen-printing machine in the sequence of carbon ink - insulator - silver ink - insulator, leading to a built-in three-electrode system; the cross sectional diagram of the resulting SPUME is shown in Figure 6(B).[47] A $20 \mu \mathrm{m}$ thick microband electrode was also fabricated using the screen printing method by J. P. Hart and coworkers.[10] The fabrication process is shown in Figure 7; a $3 \times 3 \mathrm{~mm}$ screen printed carbon electrode (SPCE) was first obtained using a commercial carbon-graphite ink.[10] The end of this electrode was cut-off perpendicular to the screen-printed carbon track to expose a $2 \mathrm{~mm}$ wide section which was then sandwiched between the dielectric and the PVC substrate.[10] A more recent screen printed graphite microband electrode was reported by C. E. Banks and co-workers for the sensing of NADH and nitrite.[11] A commercial carbon-graphite ink was screen printed onto a polyester flexible film, cured and the silver/silver chloride reference electrode was attached by screen printing $\mathrm{Ag} / \mathrm{AgCl}$ paste onto the substrate.[11] The whole surface was finally covered with a printed dielectric ink.[11] 

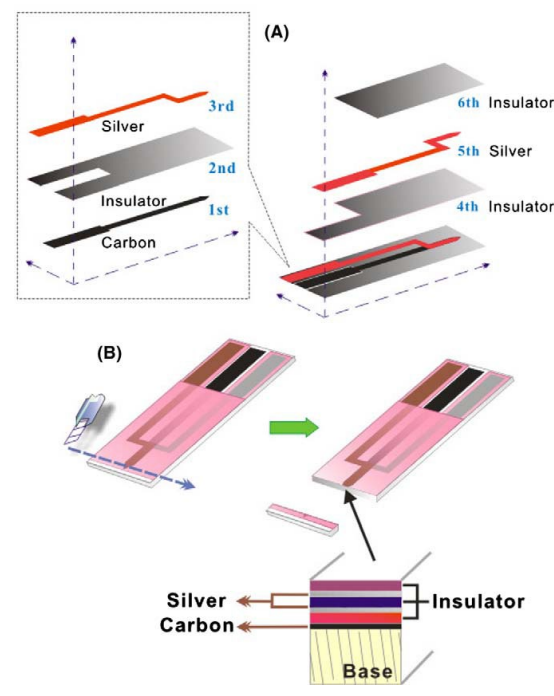

Figure 6 (A) An alternating layer-by-layer pattern structure of the SPUME assembly. (B) Cross-sectional diagram of a typical SPUME with a built-in three-electrode configuration. Adapted with permission from ref [47]. Copyright @ 2006 Elsevier.

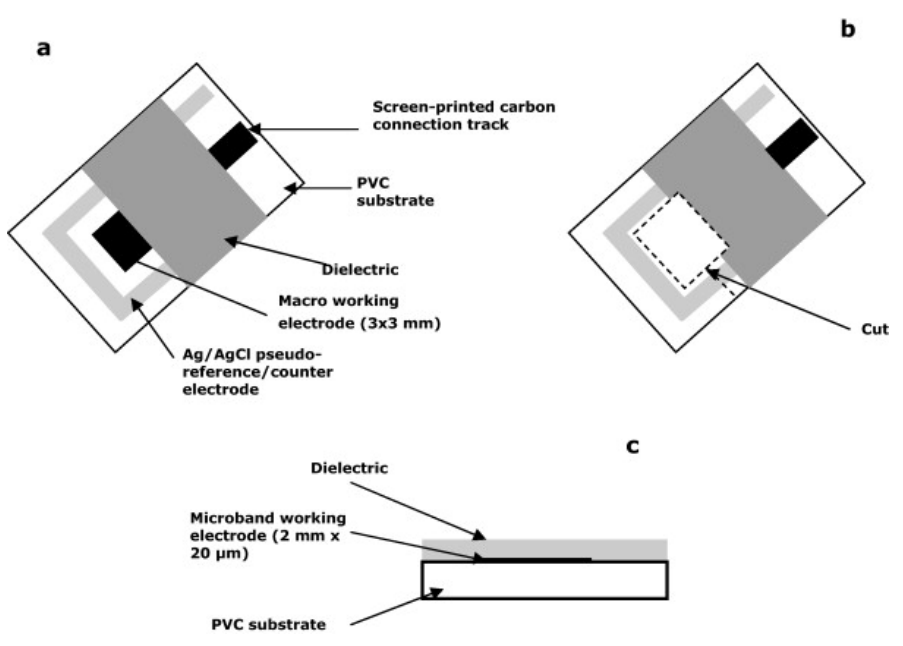

Figure 7 Diagrammatic representation of the fabrication of microband screen printed carbon electrodes (SPCE). (a) Plain view of $3 \times 3 \mathrm{~mm}$ SPCE, (b) $\mu$ BSPCE and (c) end on view of $\mu$ BSPCE. Adapted with permission from ref [10]. Copyright $\odot$ 2011 Elsevier.

\section{Fabrication of Band Arrays}

As discussed in the theory section, a band electrode array consists of multiple single bands which can have different arrangements, for example, a regular band array with parallel alignments or a regular band array with an interdigitated arrangement. Band electrode arrays are mostly fabricated using surface printed method such as lithographic techniques due to the good reproducibility. However, for "mini-arrays" which only consist of several single bands, sandwich-type band electrodes are made using the mechanical fabrication method. Two sub-sections are discussed below: "Dual or triple band electrodes" and "Microband arrays with multiple single bands". 


\section{Dual or triple band electrodes}

Dual or triple band electrodes are 'mini-arrays' comprised of just two or three single bands positioned in parallel. These electrodes can be fabricated as multiple layers of sandwiches[38,52,53,55,57,85,86], of which the fabrication method is similar to the sandwich-type single band but with multiple layers. A. J. Bard and co-workers fabricated such closely spaced ultramicroband electrodes with effective thicknesses of 0.01-6 $\mu \mathrm{m}$ by sputter deposition of Pt onto both slides of 2 to $12 \mu \mathrm{m}$ thick mica sheets that were mounted between glass slides.[57] H. A. O. Hill et al. fabricated a dual band electrode with a similar configuration as shown in Figure 8 (a) where the Au film was sputtered onto a glass substrate and the Au layers were separated by a layer of non-conducting epoxy.[53] A similar configuration was used by R. M. Wightman in which multiple band electrodes were prepared by placing one or two layers of Mylar film between several sheets of Pt foil.[55] The band width here was controlled by the number of layers of Pt foil used in the configuration.[55] Another example of such band arrays (gold, platinum, nickel and silver) with thicknesses of between 4 to $100 \mu \mathrm{m}$ were constructed by D. M. Odell et al. where the metal foil and the film of Tefzel fluoropolymer were sealed in "multidecker" sandwiches.[52] The schematic of the electrode wafer after heat-sealing is shown in Figure 8(b). The wafer was polished to expose the electrode and then fixed into a glass tube with epoxy so that the extended foil strips from the sandwich entered the tube for electrical connection.[52] The band thickness and band separation were controlled by the number of metal foils and Tefzel films used, respectively.[52]

(a)

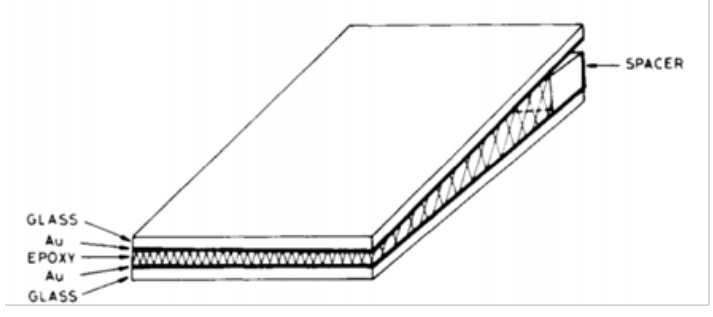

(b) $\quad \begin{gathered}\text { exposed toll strips for } \\ \text { electrical }\end{gathered}$

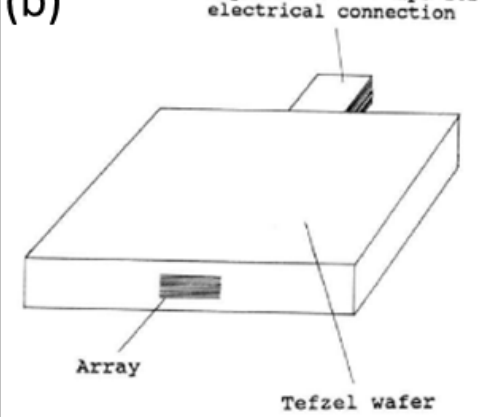

Figure 8 Schematic models of (a)[53] multi-sandwiched microband electrodes assembly and (b)[52] electrode wafer before being fixed to glass tube. Figure 8(a): adapted with permission from ref[53]. Copyright $\odot 1989$ Elsevier. Figure 8(b): adapted with permission from ref [52]. Copyright @ 1990 Elsevier.

Dual microband electrodes have also been used in a generator-collector electrode system which involves two parallel working electrodes: a "generator" and a "collector". P. N. Bartlett et al. fabricated an enzyme based on a carbon dual microband electrode, where the carbon layers were screen printed on a PVC base and the two layers of carbon was separated by dielectric layers. [87] This type of dual microband electrode has been fabricated using the screen printing method by D. E. Williams et al., as 
shown in Figure 9(a) where the two parallel bands were separated by an insulator.[88] The Au microband electrode was fabricated from commercially available ink which was screen printed onto the surface of ceramic and a fresh band could be exposed by snapping along the scribe line.[84] In this system the mass transport only came from diffusion. The electrode has been used for electrochemical "titrations" where the electrode material ink was either gold or silver depending on the analytical system studied.[84,88-90] Another generator-collector system consisting of two microband electrodes used forced convection as means of mass transport where the analyte solution flowed over the generator to the collector. Such a dual-band channel electrochemical cell was fabricated by M. Bertotti and co-workers as shown in Figure 9(b) where a small piece of recordable CD was used to construct two microband electrodes horizontally separated by a very thin gap (thickness $d$ ) in the gold layer and the planar band electrodes were embedded in a rectangular channel.[38,85,86] Interdigitated band electrode arrays are another example of generator-collector systems containing multiple bands, which is discussed in the later section.

(a)

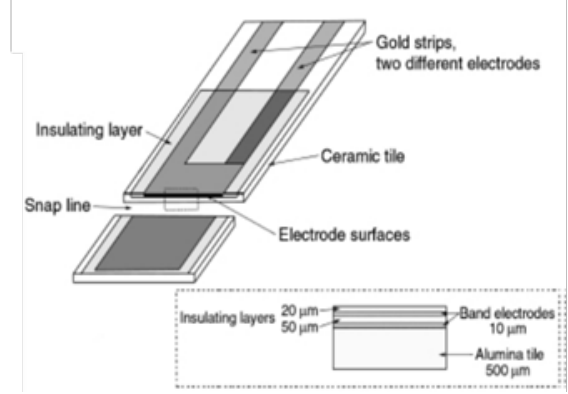

(b)

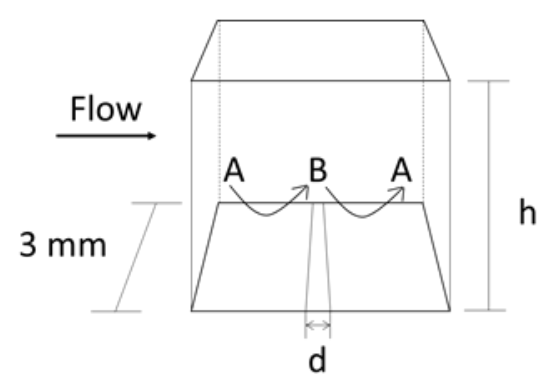

Figure 9 Schematic of (a)[88] screen printed Au dual band electrode, and (b)[85] Dual band channel electrochemical cell. Figure 9(a): Adapted with permission from Ref [88]. Copyright @ 2000 Royal Society of Chemistry. Figure 9(b): Reprinted with permission from Ref [85]. Copyright @ 2002 Elsevier.

Recently, 3D printing method has been reported to fabricate channel flow cells containing band electrodes. Snowden demonstrated microstereolithography, a 3D direct manufacturing technique to produce channel flow cells where the flow cell was assembled just by resting the microfabricated component on the electrode.[91] O'Neil et al. reported a single-step fabrication of electrochemical flow cells with embedded carbon-composite band electrodes.[92] Insulating poly(lactic acid) and a commercially available graphene-PLA composite was used simultaneously in the 3D printing process; the resulting devices gave good fabrication reproducibility within a RSD of 3\%.[92] The 3D printing method provides alternative convenient way in fabricating band electrodes for use in applications ranging from electroanalysis to electrocatalysis.

\section{Band electrode arrays with multiple single bands}


The surface printed method can be used in producing band arrays, in which case lithographic techniques[48,62,67-73,93,94] are the most frequently applied. The lithographic technology can effectively pattern and build thin film electrode materials, for example, platinum and gold on substrates with well-defined and reproducible dimensions. Band electrode arrays have different constructions: normal electrode arrays of which the electrode surface are parallel on the same plane; regular electrode arrays (REAs) with an interdigitated arrangement; and trenches where the electrode surface are slightly lower than the surrounding insulator. The discussion below starts with REAs with parallel arrangements, followed by interdigitated electrode arrays and then trenches.

A 13-microband channel flow electrode array, with electrodes ranging in size from the milimeter to the submicrometer scale, was fabricated using standard semiconductor processing method by P. J. Dobson and co-workers.[71,95] The structure of this channel electrode array is shown in Figure 10. This channel electrode array was used as a probe of mechanism and kinetics of complex electrode processes. [71] Submicroband electrode arrays with individually addressable electrodes of similar widths were fabricated by I. Fritsch and co-workers using thermal deposition of a chromium adhesion layer and a gold layer on a glass substrate, followed by plasma-enhanced chemical vapour deposition of a silicon nitride layer, photolithography and reactive ion etching.[69] The resulting band arrays were $2 \mathrm{~mm}$ long and $37.0 \mathrm{~nm}$ in width, and were characterised using contact-mode atomic force microscopy (AFM), scanning electron microscopy (SEM), surface topography and electrochemical methods.[69] Three microband electrode arrays with thicknesses of $100 \mathrm{~nm}, 1 \mu \mathrm{m}$ and $10 \mu \mathrm{m}$ were fabricated by $\mathrm{N}$. A. M. Said et al. where the electrode arrays were made using a combination of UV photolithography and e-beam lithographic methods and then applied in a transducer device.[73] A nanoscopic band electrode array was fabricated by A. O'Riordan and co-workers and then used as part of a silicon chip impedimetric immunosensor device.[68] This nanoband array consists of six nanoband electrodes spaced $800 \mu \mathrm{m}$ apart which are $700 \mathrm{~nm}$ in width, $80 \mu \mathrm{m}$ in length and $50 \mathrm{~nm}$ in height.[68]

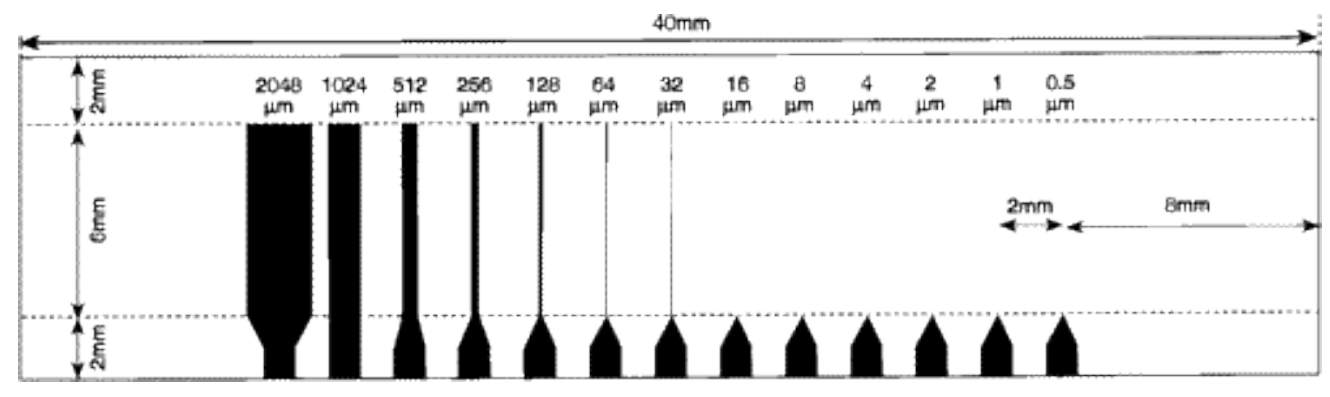

Figure 10 Schematic of the 13-electrode array. The dotted lines delineate the position of the cell into where the slide fits. The electrode length doubles sequentially from $0.5 \mu \mathrm{m}$ to $2 \mathrm{~mm}$. Adapted with permission from ref.[71]. Copyright @ 1998 American Chemical Society. 
Electrode arrays can be REAs with interdigitated bands, so called interdigitated electrode arrays. These structures can be fabricated using various methods, for example, screen printing, lamination[96], photolithography, and maskless techniques such as electron beam, focused ion beam, and nanoimprint lithography.[75] An interdigitated gold band array was produced by standard photolithographic techniques on a pyrex wafer by J. Del Campo et al.[34] The electrode array, as shown in Figure 11, consists of two sets of 250 fingers, $20 \mu \mathrm{m}$ wide and $3 \mathrm{~mm}$ long, which were recessed $1 \mu \mathrm{m}$ within the insulating surface.[34] $\mathrm{H}$. Misawa and co-workers fabricated interdigitated nanoelectrode arrays on glass substrates with controlled bandwidths ranging from $30 \mathrm{~nm}$ to $1 \mu \mathrm{m}$.[61] The high resolution electron-beam lithographic technique was used for the fabrication and followed by lift-off process.[61] An optical mix-and-match process was developed by F. J. Campo and coworkers to make interdigitated nanoband electrodes which were used to determine the heterogeneous electron transfer rate constant[75] and to construct a hydrogen peroxide biosensor[44]. The micro- and nanometric structures were fabricated by optical lithographic techniques and the bands were patterned by lift-off after a step-and-repeat lithographic process, while the active areas and contact pads on the passivation layer were defined in a mask aligner.[44,75] The corresponding fabrication process is shown in Figure 12[75]. W. M. Arrigan and co-workers fabricated recessed nanoband electrode arrays where the band electrodes were recessed within nanoscale trenches sculpted in silicon nitride passivation layers by focused ion beam milling.[48]

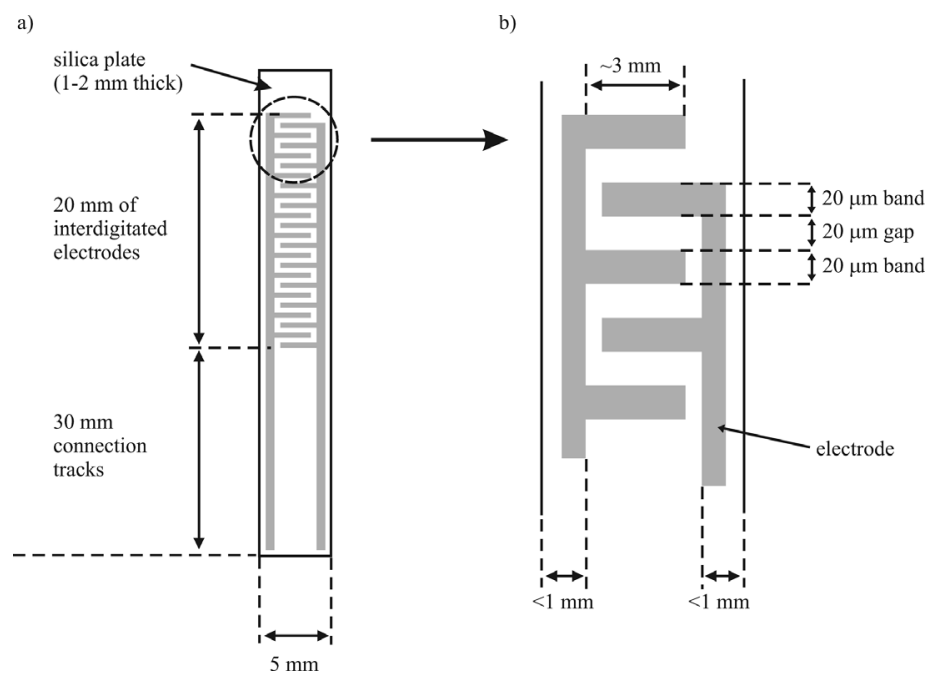

Figure 11 (a) Schematic of the RMA with an interdigitated arrangement and (b) enlargement of the RMA illustrating the electrode width and the gap width. Adapted with permission from ref [34]. Copyright @ 2007 American Chemical Society. 


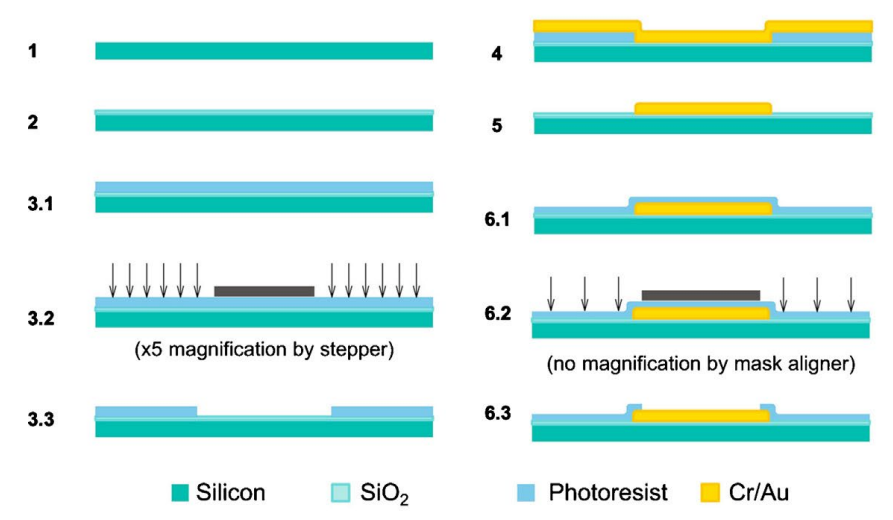

Figure 12 Diagrammatic representations of the microband array fabrication process. Adapted with permission from ref[75]. Copyright @ 2013 Elsevier.

Nanotrenches are relatively long grooves in an electrode surface with nanometer-scale dimensions in width and depth. A graphite nanotrench array was formed on the surface of the highly oriented pyrolytic graphite (HOPG) using a three-step process, the first of which was the electrodeposition of nanowires of $\mathrm{MoO}_{2}$ along the edge-plane step defects where the thickness of the nanowire was controlled by varying the deposition time.[97] The second step covered the electrode surface with an insulting polymer made by the electroreduction of nitrophenyl diazonium salts to generate nitrophenyl radicals capable of polymerising over the entire surface.[97] Finally, the $\mathrm{MoO}_{2}$ nanowires were dissolved off the HOPG surface, leaving the surrounding polymer film intact, using dilute $\mathrm{HCl}$. This revealed the nanotrenches which were typically around $8 \mathrm{~nm}$ deep, at the bottom of which, only nanobands of edge-plane graphite were exposed.[97] This method was further applied to fabricate gold nanotrench arrays; after dissolving off the $\mathrm{MoO}_{2}$ nanowires, a 200-nm-thick gold layer was evaporated on top of the nanotrenches and a supporting stub was attached to the gold layer using a cyanoacrylate adhesive.[93] The HOPG was finally cleaved as close to the gold layer as possible using a knife, resulting exposed gold nanobands surrounded by an insulating polymer layer.[93]

Micro- or nano-trench electrodes have been also applied in generator-collector systems. After the success of obtaining enhanced collection efficiencies by using a tin-doped indium oxide (ITO) - epoxy - ITO microtrench electrode[98], F. Marken and co-workers further built a microtrench sensor system on the basis of a gold-gold micro-trench electrode with ca. $70 \mu \mathrm{m}$ width and ca. $800 \mu \mathrm{m}$ depth, which gave an enhanced feedback current for hydroquinone/benzoquinone redox system in 'generatorcollector mode'.[99] The construction of the microtrench electrode is shown in Figure 13 where commercial gold coated microscope slides (100 nm thick gold layer with a titanium adhesion layer) were cut into small slides, the middle of which were then protected with non-conductive Kapton tape.[99] The unprotected gold was etched using an aqua regia solution and the remaining adhesive 
titanium layer was oxidised by putting the slides in the furnace at $500^{\circ} \mathrm{C}$ for $30 \mathrm{mins}$. The microtrench electrode was obtained by sticking the two slides together using epoxy[99]. Another similar generatorcollector system but based on two opposed Pt-coated Au film microtrench electrode with $19 \mu \mathrm{m}$ gap and either $38 \mu \mathrm{m}$ or $83 \mu \mathrm{m}$ depth was developed by F. Marken and co-workers for the titration of protons and/or hydrogen.[100]

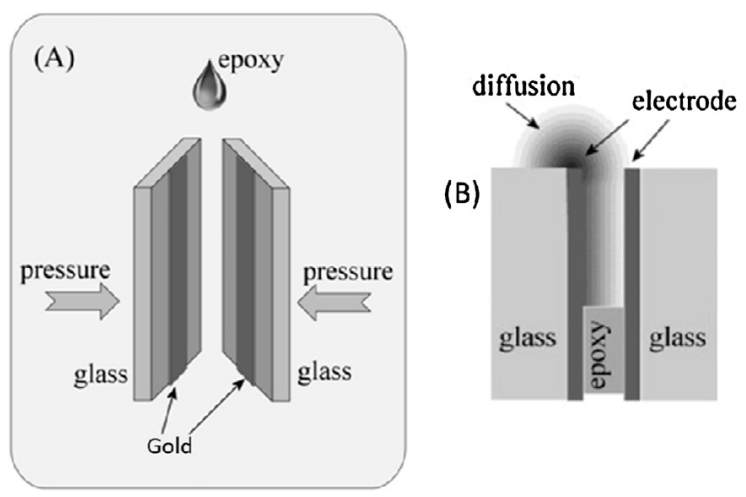

Figure 13 Schematic of the construction of the microtrench electrode. Adapted with permission from ref[100]. Copyright (c) 2014 Elsevier.

\section{Commercial Microband Electrode Arrays}

Due the reproducibility of lithographic techniques, band electrode arrays with band widths of a few micrometers have been commercialised by some companies. Table 2 tabulates commercially available microband arrays along with their electrode materials, electrode width and the suppliers. Companies notably Zimmer \& Peacock, Micrux, DropSens and ALS produce the electrode with band widths of a few micrometres. These commercial band arrays have been used in electroanalysis, flow systems and microfluidics, nanotechnology[29] and biosensors $[25,101]$. The microsquare nanoband edge electrode (MNEE) which was developed by N. J. Freeman et al.[63] has been commercialised as "NanoFlex" sold by NanoFlex Ltd (www.nanoflex.com). This electrode comprises an array of $30 \mu \mathrm{m}$ square apertures separated by $120 \mu \mathrm{m}$ (centre to centre). A $50 \mathrm{~nm}$ thick Pt nanoband electrode is sited in the centre of vertical faces of the swallow square apertures within each array element as shown in Figure 14[63]. MNEE arrays were fabricated using micro resolution photolithography where the thin metal film layer was deposited, patterned by photolithography and then selectively etched, giving reproducible and systematic control of the crucial dimensions including array element size and spacing and nanoelectrode thickness[65]. The electrical connection was achieved via the contact pad using a commercial nanoelectrode substrate holder and the substrate was then able to be immersed into the solution and to be interrogated by commercial potentiostat systems.[66] The MNEE arrays have been suggested to have improved sensitivity, selectivity and/or detection limits, notably regarding the functionalisation of the electrode surface with corresponding thiol layer towards a specific target, 
which are suitable for electrochemical and biochemical sensing[16,63,64,66,102]. However, the very thin top insulating layer (typically $300 \mathrm{~nm}$ thick silicon nitride) which was used to protect the top surface of electrode layer from electrolyte might produce significant stray capacitance, affecting the device response[64], which is a generic consideration in this area.

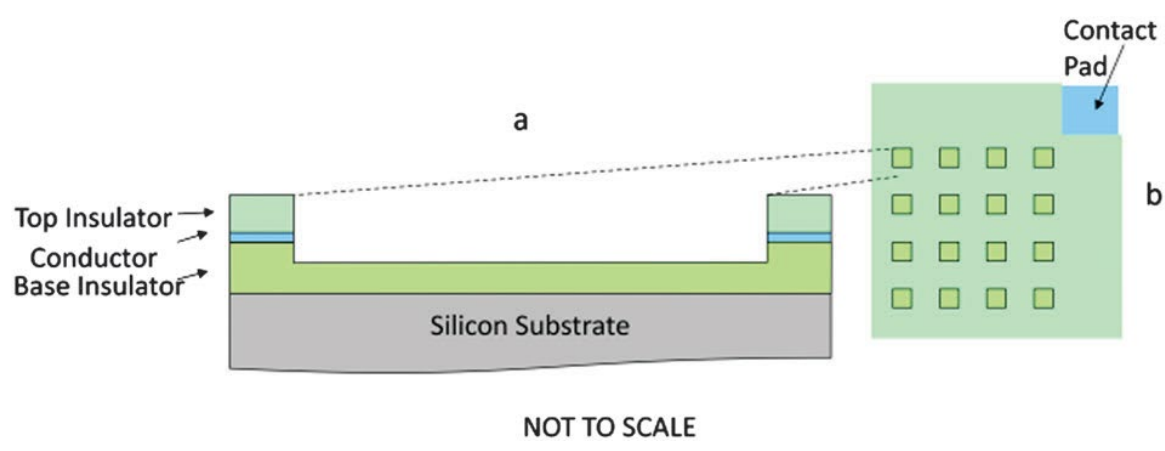

Figure 14 Schematic of 303D nanoband electrode substrate. The electrode comprises of an array of electrodes in the inner walls of the apertures comprising a single conducting layer (Pt) $50 \mathrm{~nm}$ thick. (a) Single square aperture in cross-section, (b) plan view of complete substrate. The apertures were $30 \mu \mathrm{m} \times 30 \mu \mathrm{m}$ separated by $120 \mu \mathrm{m}$ centre to centre in a square array of $42 \times 42$ apertures. Adapted with permission from ref. [63]. Copyright $@ 2013$ Royal Society of Chemistry.

Table 2 List of commercially available single microband and microband arrays.

\begin{tabular}{|c|c|}
\hline Supplier & Electrodes \\
\hline $\begin{array}{l}\text { Zimmer \& Peacock } \\
\text { www.zimmerpeacocktech.com }\end{array}$ & IDA-Au/Pt $(5 \mu \mathrm{m}, 10 \mu \mathrm{m})$ \\
\hline $\begin{array}{l}\text { Micrux Technologies } \\
\text { www.micruxfluidic.com/en }\end{array}$ & IDA-Au $(5 \mu \mathrm{m}, 10 \mu \mathrm{m})$ \\
\hline $\begin{array}{l}\text { DropSens } \\
\text { www.dropsens.com }\end{array}$ & IDA-Au/Pt $(5 \mu \mathrm{m}, 10 \mu \mathrm{m}), \mathrm{IDA}-\mathrm{Ag} / \mathrm{Cu}(105 \mu \mathrm{m}, 10 \mu \mathrm{m})$ \\
\hline $\begin{array}{l}\text { ALS } \\
\text { www.als-japan.com }\end{array}$ & IDA-Au $(2 \mu \mathrm{m}, 3 \mu \mathrm{m}, 10 \mu \mathrm{m})$, IDA-C $(10 \mu \mathrm{m})$ \\
\hline $\begin{array}{l}\text { NanoFlex } \\
\text { www.nanoflex.com } \\
\text { (discontinuous; active on } 26^{\text {th }} \text { June, } \\
\text { 2019) }\end{array}$ & 303D Pt nanoband (50 nm) \\
\hline
\end{tabular}

*IDA represents "interdigitated electrode arrays".

\section{Band Electrodes in Sensing Applications}

Microband electrodes have been fabricated as sensors providing the advantages of small double layer capacitance, low ohmic drop, efficient mass transport due to convergent diffusion and higher current 
densities, which lead to sensors with improved signal-to-noise ratios, better sensitivities and lower detection limits.[2,5] This section summaries sensing applications from recent years (later than 2010) using microband electrodes with two subsections: chemical sensors and biosensors.

\section{Chemical sensors}

Chemical sensors are one type of the devices which allows the direct transduction of the concentration of a chemical species into an electrical signal. Such a sensor is concerned with detecting and measuring a specific chemical substrate or set of chemicals.[8]

Chemical sensors have been widely used in the detection of target species in environmental analysis such as water quality. Dudeney et al. fabricated a portable sensor for the detection of As(III) in drinking water based on a screen printed microband electrode.[103] This sensor was able to reach a low LOD of $0.8 \mathrm{ppb}$ (in $4 \mathrm{M} \mathrm{HCl}$ electrolyte), which is lower than the World Health Organisation limit of $10 \mu \mathrm{g} \mathrm{L}^{-1}(\mathrm{ppb})[103]$, offering a cost effective device with a high sensitivity for arsenic analysis in drinking water. Xia and his co-workers reported several papers on the analysis of water based on microband electrode arrays.[104-106] In one, a microsensor based on gold microband array for the determination of phosphate in fresh water was fabricated where gold nanoparticles (AuNPs) were deposited on the electrode surface to improve the sensitivity.[104] The fabrication process and the structure of the electrode is shown in Figure 15; the modified electrode gave a sensitivity of $7.66 \mu \mathrm{A}$ per (mg P.L) which is three time larger than the unmodified electrode.[104] Second a palladium-Tin modified microband electrode array was developed for nitrate detection in fresh water with a long life time of over 60 days.[105] This sensor was able to detect nitrate in the range of $1 \mathrm{mg} \mathrm{L}^{-1}$ to $20 \mathrm{mg}$ $\mathrm{L}^{-1}$ with a sensitivity of $398 \mu \mathrm{A} /\left(\mathrm{mg} \mathrm{L}^{-1} \mathrm{~cm}^{2}\right)$.[105] Most recently, the same group developed a chemical sensor for nitrate detection based on an ultramicro IDA modified by Pd-AuNPs. [106] The sensing layer (Pd-AuNPs) was electrodeposited on the electrode surface and showed a good linearity from $1 \mathrm{mg} \mathrm{L}^{-1}$ to $15 \mathrm{mg} \mathrm{L}^{-1}$ in neutral water conditions.[106] 


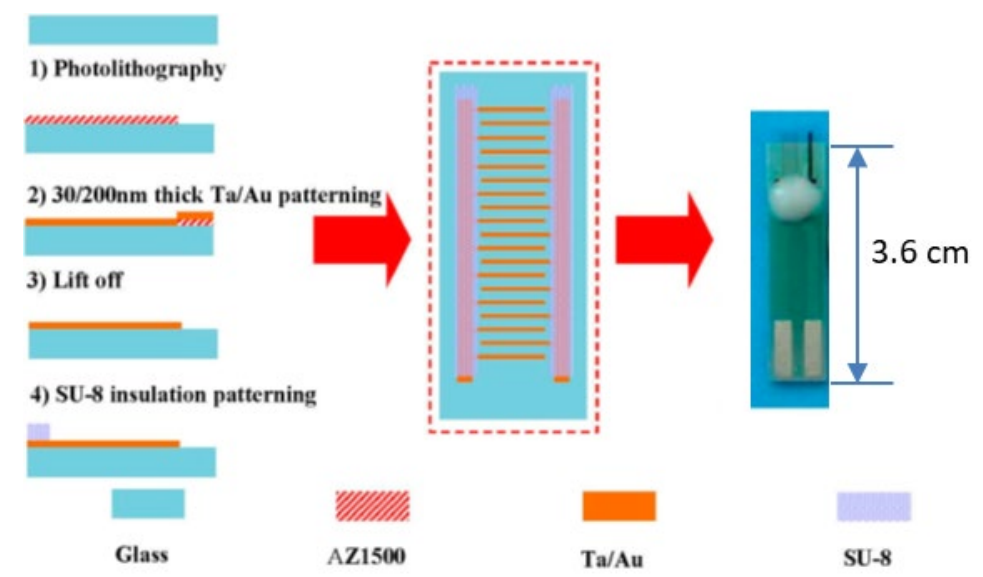

Figure 15 The fabrication process and a photograph of a gold microband array electrode. The diameter of the coin is 19 $\mathrm{mm}$. The picture was adapted form ref [104]. Copyright (C) 2014 by the authors.

Gold nanowire electrodes made using 'nanoskiving', as described in Figure 5, were used as nanosensors to monitoring hydrogen peroxide released from cells simulated by ascorbic acid, providing a high sensitivity and selectivity.[9] Hart and his co-workers fabricated a disposable chemical sensor based on a screen printed carbon microband electrode without further modification to detect lead in acetate leachates from glazed ceramic plates.[10] This $\mu$ BSPCE has the ability to manufacture highly reproducible sensors in large numbers.[10] The fabrication process is schematically shown in Figure 7.[10] Another graphite-SPE which was $10 \mathrm{~mm}$ in length and $100 \mu \mathrm{m}$ in width was used in the electroanalytical application for the sensing of NADH and nitrite by Banks and his co-workers.[11] Salama and his co-workers fabricated a capacitive sensor for the detection of humidity and volatile organic compounds based on a prototypical metal-organic framework (MOF) coated IDA.[12] This 2D periodic porous structure is based on the assembly of copper ions and benzene dicarboxylate ligand and is grown as a thin film on the surface of the electrode.[12] Another MOF-based sensor for the detection of $\mathrm{SO}_{2}$ was developed in the same research group, where the sensing layer based on an indium MOF, namely MFM-300, was coated on a functionalised capacitive interdigitated electrode.[12] It was shown that this resulting sensor provided a high sensitivity to $\mathrm{SO}_{2}$ at concentrations down to 75 ppm with a lower detection limit to be around 5 ppb.[12]

\section{Biosensors}

Biosensors are a sub-section of chemical sensors in which the recognition system utilises a biochemical mechanism.[107] In this section, we divide biosensors into three categories on the basis of the biological analyte in the measured system: glucose biosensors, protein biomark biosensors and other biosensors. 
Glucose biosensors - Most glucose biosensors are fabricated on electrodes functionalised with glucose oxidase (GOx) enzyme[13-16]. The amperometric response is generated by the glucose biosensors, in the presence of glucose oxidase and a mediator. J. P. Hart and his co-workers fabricated glucose biosensors based on a screen printed microband electrode from a water-based carbon ink containing cobalt phthalocynine redox mediator and GOx enzyme for real-time monitoring of glucose levels in cell cultures.[13,14] The microband electrodes with widths of 100-400 $\mu \mathrm{m}$, as shown in Figure 16, give steady-state responses, allowing the measurements in quiescent sample solutions and continuous monitoring applications. Another microband biosensor was subsequently reported for the determination of galacose taken up by hepacellular carcinoma cells.[17] The cells were incubated with $10 \mathrm{mM}$ galactose and various concentrations of paracetamol for $24 \mathrm{~h}$ before measurements.[18] Compared to a conventionally sized biosensor $\left(7.00 \mu \mathrm{A} \mathrm{mM}^{-1} \mathrm{~cm}^{-2}\right)$, this reported biosensor gives a slightly greater sensitivity $\left(7.27 \mu \mathrm{A} \mathrm{mM}^{-1} \mathrm{~cm}^{-2}\right)$ to galactose.[18] Sharma et al. fabricated a glucose sensor based on carbon interdigitated array nanoelectrodes using photolithographic techniques where one comb of the IDA was modified with GOx while the other comb remained unmodified.[15] The sensitivity and LOD was improved by reducing the gap between the two combs of the IDA.[15] Falk et al. developed a high sensitivity glucose biosensor based on Pt MNEE arrays where the surface of nanoband electrodes was modified with GOx.[16] A high sensitivity $\left(263 \mu \mathrm{A} \mathrm{mM} \mathrm{m}^{-1} \mathrm{~cm}^{-2}\right)$ and low LOD $(<3 \mu \mathrm{M})$ was achieved due to the increased mass transport on nanoband electrodes.[16] Recently, a glucose biosensor was fabricated on a Prussian blue (PB)-modified IDA (Au/PB-Pt IDA) using a photolithographic techinique by Ohnuki et al. and the resulting Au/PB-Pt IDA was then functionalised with GOx to obtain $\mathrm{Au} / \mathrm{PB} / \mathrm{GOx}-\mathrm{Pt}$ IDA as a glucose sensor.[19] Unlike the pre-mentioned glucose biosensors which are based on a functionalised electrode, another glucose biosensor based on an unmodified gold nanowire electrode array was fabricated using a hybrid electron beamphotolithography process by Dawson et al.[20] The mediator used in the detection of glucose is ferrocene monocarboxylic acid ( $\mathrm{FCCOOH}$ ) with the presence of GOx.[20] The resulting biosensor can be applied to quantify glucose in the concentration range of $10 \mu \mathrm{M}-100 \mathrm{mM}$, with an extremely high sensitivity of $7.2 \mathrm{~mA} \mathrm{mM}^{-1} \mathrm{~cm}^{-2}$ and a low detection limit of $3 \mu \mathrm{M}(\mathrm{S} / \mathrm{N}=3)$.[20] 


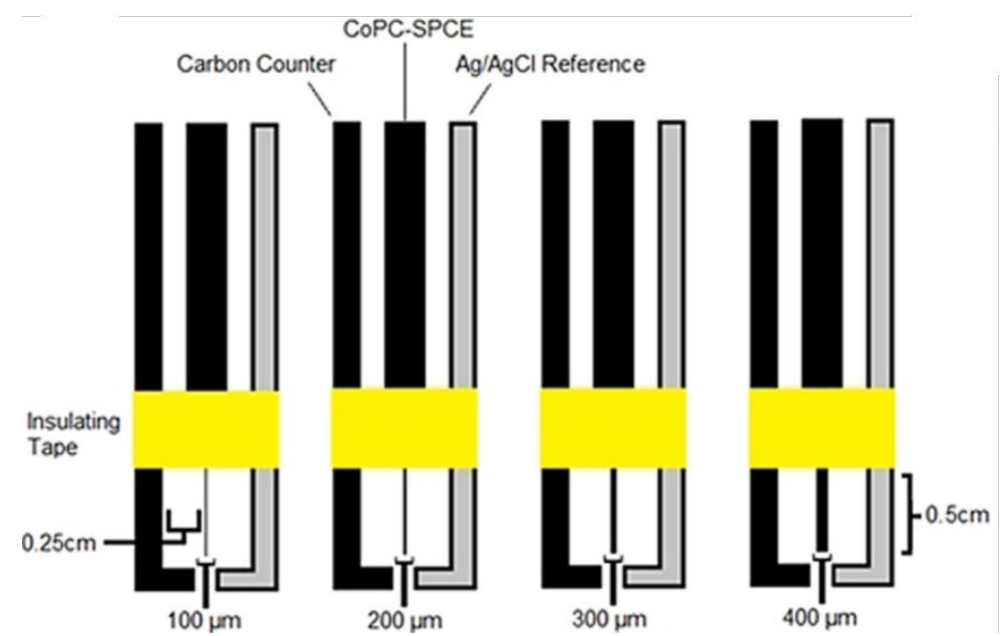

Figure 16 Figure illustrating the screen-printed electrode configuration. The distance between the counter-working and working-reference was $0.25 \mathrm{~cm}$. The electrode were printed onto PVC, which is designated by the white background. The yellow bar indicates the insulating tape used to define the electrode area. Adapted with permission from ref [14]. Copyright @ 2018 Wiley-VCH Verlag GmbH \& Co. KGaA, Weinheim.

Protein biomarker biosensors - Qureshi et al. fabricated a label-free capacitive biosensor to detect multiple disease biomarkers based on a gold-IDA functionalised with different antibodies (e.g. Creactive protein, TNF $\alpha$ and IL6 antibodies).[21] The gold-IDA chip was fabricated using lithographic techniques with the immobilisation of antibodies on gold-IDA electrode surface with arrays of both pure antibodies and multiple antibodies in equimolar ratios.[21] Ohno et al. utilised a Au-IDA in electrochemical impedance spectroscopy (EIS) to build a label-free human immunoglobulin A (IgA) immunosensor.[22] The Au-IDA with 130 fingers of $8 \mathrm{~mm}$ length and $20 \mu \mathrm{m}$ width, separated with a 20 $\mu \mathrm{m}$ gap between adjacent fingers, was fabricated using photolithographic techniques and the anti-IgA was covalently immobilised on the electrode surface through a self-assembled monolayer.[22] This immunosensor is used in the concentration range of $0.01-100 \mathrm{ng} \mathrm{mL}^{-1}$ with the lowest detection limit among EIS based IgA biosensors studies and with a high selectivity for IgA.[22] Pyun and his co-workers reported a capacitive biosensor based on an IDA with nanoislands.[108] A parylene film with amine groups was then coated on the IDA with nanoislands to covalently immobilise proteins providing a high immobilisation efficiency of receptor molecules and hence enhance the sensitivity of capacitive detection.[108] The structure of IDA with nanoislands and the fabrication process is shown in Figure 17.[108] This biosensor was successfully tested using the hepatitis B virus surface antigen as a model analyte within the concentration range of $0.1-1000 \mathrm{ng} \mathrm{mL}^{-1}$ with a LOD of less than $100 \mathrm{pg} \mathrm{mL}^{-1}$.[108] Creedon et al. developed a label-free impedimetric nanoband sensor to detect bovine viral diarrhoea (BVD) disease target molecules.[68] The chip used in the sensor comprised of six individually addressable gold nanobands which are bio-modified using target molecules (BCD-antibody or BVD virus).[68] This sensor gives a low time-to-result (20 mins) and high selectivity in discriminating 
between disease positive and disease negative serum samples from both transiently and permanently infected calves.[68]

(a)

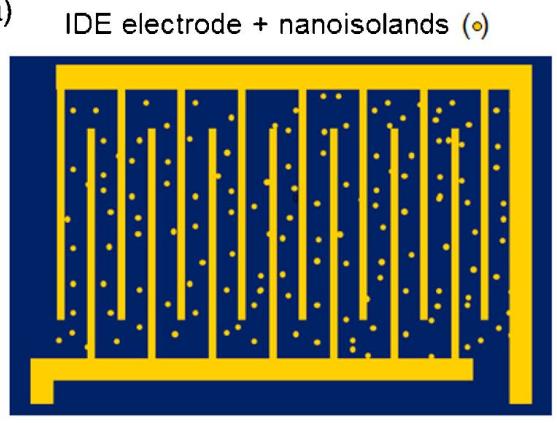

(b)

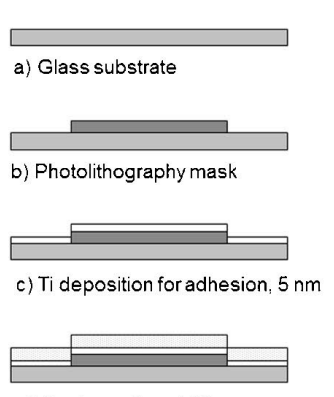

d) Au deposition, $100 \mathrm{~nm}$

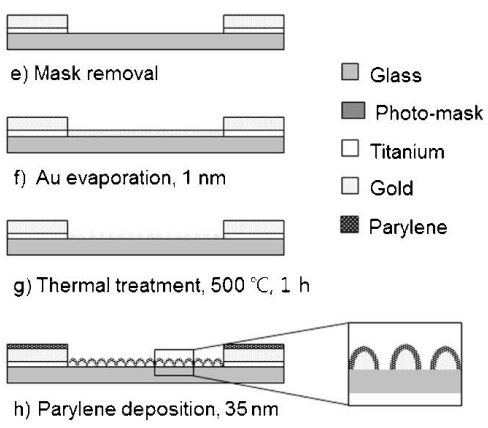

Figure 17 (a) Schematic of IDA with nanoislands. (b) Fabrication process of parylene-A coated IDA with nanoislands. After IDA fabrication by a standard UV-photolithography process, nanoislands were produced by thermal evaporation of a gold layer $(1 \mathrm{~nm})$ and heat treatment $\left(500^{\circ} \mathrm{C}, 1 \mathrm{~h}\right)$. Adapted with permission from ref [108]. Copyright $@ 2014$ Elsevier.

Other biosensors - Wang et al. developed a DNA capacitive biosensor based on a gold-IDA functionalised with a DNA probe.[25] The biosensor has the ability to detect complementary DNA fragments with a detection limit down to 20 DNA target molecules (1.5 aM range) and a wide dynamic range between $1 \mu^{-1}$ and $10^{6} \mu^{-1}$ target molecules, which provides possibilities and advantages for sample analysis in a typical clinical application environment.[25] The gold-IDA was also used to fabricate an electrochemical aptasensor for the detection of interferon-gamma (IFN- $\Upsilon$ ) by immobilising a RNA aptamer capture probe (ACP), which is selective to IFN- $r$.[101] In order to improve the hybridisation efficiency and the reproducibility of the biosensors. The electrode surface was further functionalised with mixed self-assembled monolayers in conjunction with a thiol-derivatized DNA or ACP and spacer thiols, resulting in a ternary monolayer, as shown in Figure 18.[101] The resulting functionalised Au-IDA was able to measure IFN- $\Upsilon$ in fetal bovine serum solution with a linear sensing range from $22.22 \mathrm{pM}$ to $0.11 \mathrm{nM}\left(1-5 \mathrm{ng} \mathrm{mL}^{-1}\right)$ and a detection limit of $11.56 \mathrm{pM}$.[101] Another aptasensor was used to detection cocaine in human serum, using a series of parallel microband electrodes by Oueslati et al.[109] This sensor has a sample-to-result time of $30 \mathrm{~s}$, a LOD of 7.8 fM,[109] which solved the problems of most current cocaine detection methods, which are, for example, timeconsuming and require of expensive equipment. An enzyme-based hydrogen peroxide biosensor was fabricated on IDA with $1 \mu \mathrm{m}$ band widths and $1 \mu \mathrm{m}$ gaps on the surface of which was immobilised horseradish peroxidase by Kuo et al.[44] The resulting biosensor exhibits a sensitivity of $114.75 \mathrm{~A} \mathrm{M}^{-1}$ $\mathrm{cm}^{-2}$, a detection limit of $9.96 \mu \mathrm{M}$ and a linear range up to $500 \mu \mathrm{M}$.[44] Sekretaryova et al. reported a screen printed laccase-based graphite microband array biosensor for in situ detection of phenol in weakly supported media.[110] The biosensor showed an improved sensitivity of $1.35 \pm 0.4 \mathrm{~A} \mathrm{M}^{-1} \mathrm{~cm}^{-2}$ 
in the concentration range of $0.2-10 \mu \mathrm{M}$ for phenol estimation in waste water and for water quality monitoring without additional sample treatment.[110] Laczka et al. reported a one-step sandwich immunoassay for the detection of pathogen bacteria using a microchannel flow cell, where the system combined immunomagnetic capture and amperometric detection together.[60] The electrochemical monitoring of the activity of horseradish peroxidase, an enzyme label, through its catalysis of hydrogen peroxide in the presence of the mediator hydroquinone is comprised of the basis of the detection.[60] The reported assay on the detection of Escherichia coli could be done in a concentration range between $10^{2}$ and $10^{8}$ cell $\mathrm{mL}^{-1}$ with an LOD of $55 \mathrm{cell} \mathrm{mL}^{-1}$.[60]

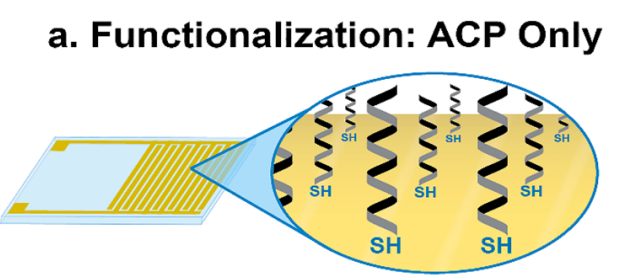

\section{b. Functionalization: ACP + Thiol Backfiller}

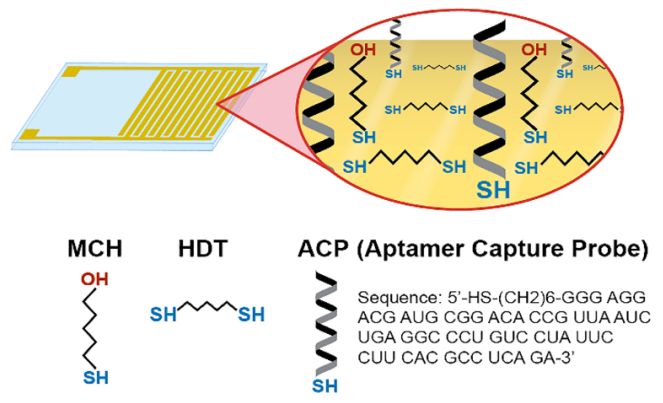

Figure 18 Bio-functionalisation scheme of the gold-IDA. Magnified view showing bio-functionalisation with (a) the aptamer capture probe (ACP) and (b) ACP with 1,6-hexanedithiol and 6-mercapto-1-hexanolphosphate which forms the ternary monolayer structure. Adapted with permission from ref [101]. Copyright @ 2017 American Chemical Society.

The performance of sensors based band electrodes are closely related to their fabrication. In general, three of the characteristics of sensors which are of most concern are: sensitivity, limit of detection and selectivity. Interdigitated electrodes are usually applied in the fabrication of sensors; as described in theoretical section, where the band width $(w)$ and the inter-band separation ( $\delta_{\text {inter-band }}$ ) are the two key parameters when fabricating electrode arrays. The thinner the band width is, the faster the mass transport of the species and the smaller the capacitance is. Higher total current output can be easily varied by increasing the band length or the number of individual bands within the array. This leads to higher Faradaic to capacitive current ratios, higher signal-to-noise ratios which provides improved sensitivities and lower detection limit. Moreover, bearing in mind that the compromise for band width and inter-band separation as described in theoretical section, reducing the inter-band separation or the gap between the two combs for interdigitated electrode increases the diffusional flux of redox species and hence gives improved sensitivities and faster response at the collector. For example, 
Sharma et al. found that the current response at the collector (comb 2 in interdigitated electrode) was ca. 4.5 times larger when the inter-electrode gap decreased from $2.4 \mu \mathrm{m}$ to $1.9 \mu \mathrm{m}$ for a glucose biosensor using functionalised gold-IDA.[15] In addition, the sensitivity and selectivity of sensors can be improved by modification of electrode surface. For example, the sensitivity of AuNPs modified goldIDA for phosphate detection was improved from $2.40 \mu \mathrm{A}$ per (mg P/L) to $7.66 \mu \mathrm{A}$ per (mg P/L) compared to the unmodified microsensor.[104] The selectivity can be achieved mostly by immobilising specific receptors onto the electrode surface such as enzymes[13-16,19,20,44] and antibodies[21,68,108].

\section{Conclusions and Perspectives}

This review has summarised the fabrication methods and sensing applications for single microband electrodes and microband arrays. Band electrodes find many and diverse uses in sensing applications due to their advantageous mass transport through convergent diffusion, high current densities, low ohmic drop, higher signal-to-noise ratios and hence improved sensitivity and lower detection limits. The fabrication methods for band electrodes have been summarised with single micro- or nano-band electrodes regularly constructed in a 'sandwich' configuration where the conductive band layer is sealed between two insulating layers. Depending on the deposition method of conductive layer, the thickness varies from micrometers to sub-nanometers. Thinner band layers are achieved by using thermal evaporation of conductive materials onto the insulating substrate. The sandwich configuration can be obtained by covering another insulating layer using adhesive epoxy or hot press method. However, with this fabrication method it is hard to identify the thickness of the electrode due to the uneven coverage and therefore was mostly used to construct single band electrodes. Microband arrays have been constructed using lithographic techniques or again, sandwiching a band layer between two insulating layers. In order to reproducibly fabricate band arrays, lithographic techniques are mostly used and also applied in the commercialised band arrays. The main drawback of these method are the long preparation time and the requirement of costly equipment. The fabrication of nanoscopic single band or band arrays has been reported much less than that of microband electrodes. In general, although the core idea of fabrication for band electrodes has not changed much over the years, thinner bands have been made using improved techniques. Moreover, most commercialised band electrodes are microband arrays rather than single microband electrodes. Finally we note an easier, practical and reproducible method for making nanoscopic band electrodes is still needed.

Among all the fabrication methods, metal- or carbon-based interdigitated electrode arrays are mostly applied in the construction of sensing devices. The opportunity for the easy modification of the surface 
of band electrodes, especially interdigitated electrode arrays expands their uses as sensors. Biosensors based on band electrodes can be used to detect various analytes by immobilising specific receptor species, where for example, the surface of the electrode is functionalised with glucose oxidase for glucose detection. The modifications includes, for example, the coating of metal-organic framework (MOF) thin layers[12,111] and metal oxide embedded in substrates[112]. The band electrode modification provides more possibilities of the applications and improve their performances in diverse applications.

\section{Acknowledgements}

We thank Chuhong Lin for the home-written simulation programme used to model for single microbands and microband arrays. D. Li thanks the China Scholarship Council and the University of Oxford for supporting her DPhil research.

\section{Vocabulary}

Band electrodes, electrodes with a band geometry which are normally macroscopic in one dimension and microscopic or nanoscopic in the other; band array, an array comprising of multiple individual bands which can be connected in various format; interdigitated electrodes, electrodes consisting of two arrays which are interlaced in a comb-like structure; chemical sensors, one type of the sensing devices which allows the direct transduction of the concentration of a chemical species into an electrical signal; biosensors, a sub-section of chemical sensors in which the recognition system utilises a biochemical mechanism.

\section{Abbreviations}

IUPAC, the International Union of Pure and Applied Chemistry; LOD, limit of detection; CNTs, carbon nanotubes; PTFE, polytetrafluoroethylene; BDD, boron-doped diamond; SPUMEs, screen printed ultramicroband electrodes; SPCE, screen printed carbon electrode; $\mu \mathrm{BSPCE}$, microband screen printed electrode; AFM, atomic force microscopy; SEM, scanning electron microscopy; HOPG, highly oriented pyrolytic graphite; ITO, indium tin oxide; MNEE, microsquare nanoband edge electrode; IDA, interdigitated electrode array; AuNPs, gold nanoparticles; MOF, metal-organic framework; GOx, glucose oxidase; PB, Prussian blue; IgA, immunoglobulin A; IFN- $\Upsilon$, interferon- $\Upsilon$; ACP, aptamer capture probe

\section{References:}

[1] K. Stulík, C. Amatore, K. Holub, V. Marecek, W. Kutner, Microelectrodes. Definitions, characterization, and applications (Technical report), Pure Appl. Chem. 72 (2000) 1483-92. 
doi:10.1351/pac200072081483.

[2] J. Heinze, Ultramicroelectrodes in Electrochemistry, Angew. Chemie Int. Ed. English. 32 (1993) 1268-1288. doi:10.1002/anie.199312681.

[3] R.J. Forster, Microelectrodes : New Dimensions in Electrochemistry, Chem. Soc. Rev. 23 (1994) 289-297.

[4] R.G. Compton, C.E. Banks, Understanding Voltammetry, 3rd Edn, World Scientific, Singapore, 2018. doi:doi:10.1142/q0155.

[5] K.R. Wehmeyer, M.R. Deakin, R.M. Wightman, Electroanalytical Properties of Band Electrodes of Submicrometer Width, Anal. Chem. 57 (1985) 1913-1916. doi:10.1021/ac00286a026.

[6] I.A. Sliver, Microelectrodes in medicine, Phil. Trans. R. Soc. Lond. B316 (1987) 161-167.

[7] E. Llaudet, S. Hatz, M. Droniou, N. Dale, Microelectrode biosensor for real-time measurement of ATP in biological tissue, Anal. Chem. 77 (2005) 3267-3273. doi:10.1021/ac048106q.

[8] J. Fraden, Chemical Sensors, Handb. Mod. Sensors. (2010) 569-606. doi:10.1007/978-1-44196466-3.

[9] W. Qiu, M. Xu, R. Li, X. Liu, M. Zhang, Renewable and Ultralong Nanoelectrochemical Sensor: Nanoskiving Fabrication and Application for Monitoring Cell Release, Anal. Chem. 88 (2016) 1117-1122. doi:10.1021/acs.analchem.5b04055.

[10] K.C. Honeychurch, S. Al-Berezanchi, J.P. Hart, The voltammetric behaviour of lead at a microband screen-printed carbon electrode and its determination in acetate leachates from glazed ceramic plates, Talanta. 84 (2011) 717-723. doi:10.1016/j.talanta.2011.01.073.

[11] J.P. Metters, R.O. Kadara, C.E. Banks, Electroanalytical properties of screen printed graphite microband electrodes, Sensors Actuators, B Chem. 169 (2012) 136-143. doi:10.1016/j.snb.2012.04.045.

[12] C. Sapsanis, H. Omran, V. Chernikova, O. Shekhah, Y. Belmabkhout, U. Buttner, M. Eddaoudi, K.N. Salama, Insights on capacitive interdigitated electrodes coated with MOF thin films: Humidity and VOCs sensing as a case study, Sensors (Switzerland). 15 (2015) 18153-18166. doi:10.3390/s150818153.

[13] R.M. Pemberton, J. Xu, R. Pittson, G.A. Drago, J. Griffiths, S.K. Jackson, J.P. Hart, A screenprinted microband glucose biosensor system for real-time monitoring of toxicity in cell 
culture, Biosens. Bioelectron. 26 (2011) 2448-2453. doi:10.1016/j.bios.2010.10.030.

[14] G. Hughes, R.M. Pemberton, P. Nicholas, J.P. Hart, Fabrication of Miniaturised Screen-printed Glucose Biosensors, Using a Water-based Ink, and the Evaluation of their Electrochemical Behaviour, Electroanalysis. 30 (2018) 1608-1612. doi:10.1002/elan.201800104.

[15] D. Sharma, Y. Lim, Y. Lee, H. Shin, Glucose sensor based on redox-cycling between selectively modified and unmodified combs of carbon interdigitated array nanoelectrodes, Anal. Chim. Acta. 889 (2015) 194-202. doi:10.1016/j.aca.2015.07.048.

[16] M. Falk, R. Sultana, M.J. Swann, A.R. Mount, N.J. Freeman, Nanoband array electrode as a platform for high sensitivity enzyme-based glucose biosensing, Bioelectrochemistry. 112 (2016) 100-105. doi:10.1016/j.bioelechem.2016.04.002.

[17] P. Kanyong, G. Hughes, R.M. Pemberton, S.K. Jackson, J.P. Hart, Amperometric Screen-Printed Galactose Biosensor for Cell Toxicity Applications, Anal. Lett. 49 (2016) 236-244. doi:10.1080/00032719.2015.1070166.

[18] G. Hughes, K. Westmacott, K.C. Honeychurch, A. Crew, R.M. Pemberton, J.P. Hart, Recent advances in the fabrication and application of screen-printed electrochemical (bio)sensors based on carbon materials for biomedical, agri-food and environmental analyses, Biosensors. 6 (2016). doi:10.3390/bios6040050.

[19] H. Ohnuki, T. Wako, B. Mecheri, H. Wu, D. Tsuya, H. Endo, Self-powered hydrogen peroxide sensor and its application as a biosensor, Jpn. J. Appl. Phys. 58 (2019). doi:10.7567/13474065/ab01d2.

[20] K. Dawson, M. Baudequin, A. O'Riordan, Single on-chip gold nanowires for electrochemical biosensing of glucose, Analyst. 136 (2011) 4507-4513. doi:10.1039/c1an15279c.

[21] A. Qureshi, J.H. Niazi, S. Kallempudi, Y. Gurbuz, Label-free capacitive biosensor for sensitive detection of multiple biomarkers using gold interdigitated capacitor arrays, Biosens. Bioelectron. 25 (2010) 2318-2323. doi:10.1016/j.bios.2010.03.018.

[22] R. Ohno, H. Ohnuki, H. Wang, T. Yokoyama, H. Endo, D. Tsuya, M. Izumi, Electrochemical impedance spectroscopy biosensor with interdigitated electrode for detection of human immunoglobulin A, Biosens. Bioelectron. 40 (2013) 422-426. doi:10.1016/j.bios.2012.07.052.

[23] P. Mehrotra, Biosensors and their applications - A review, J. Oral Biol. Craniofacial Res. 6 (2016) 153-159. doi:10.1016/j.jobcr.2015.12.002. 
[24] J. Wang, G. Chen, M.P. Chatrathi, A. Fujishima, D.A. Tryk, D. Shin, Microchip capillary electrophoresis coupled with a boron-doped diamond electrode-based electrochemical detector, Anal. Chem. 75 (2003) 935-939. doi:10.1021/ac0262053.

[25] L. Wang, M. Veselinovic, L. Yang, B.J. Geiss, D.S. Dandy, T. Chen, A sensitive DNA capacitive biosensor using interdigitated electrodes, Biosens. Bioelectron. 87 (2017) 646-653. doi:10.1016/j.bios.2016.09.006.

[26] A.M. Bond, M. Fleischmann, J. Robinson, Electrochemistry in organic solvents without supporting electrolyte using platinum microelectrodes, J. Electroanal. Chem. 168 (1984) 299312. doi:10.1016/0368-1874(84)87106-3.

[27] M.A. Hernández-Olmos, L. Agüí, P. Yáñez-Sedeño, J.M. Pingarrón, Analytical voltammetry in low-permitivity organic solvents using disk and cylindrical microelectrodes. Determination of thiram in ethyl acetate, Electrochim. Acta. 46 (2000) 289-296. doi:10.1016/S00134686(00)00584-3.

[28] F. Zhang, M.A. Edwards, R. Hao, H.S. White, B. Zhang, Collision and Oxidation of Silver Nanoparticles on a Gold Nanoband Electrode, J. Phys. Chem. C. 121 (2017) 23564-23573. doi:10.1021/acs.jpcc.7b08492.

[29] X. Li, C. Batchelor-McAuley, L. Shao, S. V. Sokolov, N.P. Young, R.G. Compton, Quantifying Single-Carbon Nanotube-Electrode Contact via the Nanoimpact Method, J. Phys. Chem. Lett. 8 (2017) 507-511. doi:10.1021/acs.jpclett.6b02899.

[30] A. Szabo, D.K. Cope, D.E. Tallman, P.M. Kovach, R.M. Wightman, Chronoamperometric current at hemicylinder and band microelectrodes: Theory and experiment, J. Electroanal. Chem. 217 (1987) 417-423. doi:10.1016/0022-0728(87)80233-4.

[31] R.M. Wightman, Voltammetry with microscopic electrodes in new domains, Science (80-. ). 240 (1988) 415-420. doi:10.1126/science.240.4851.415.

[32] A.J. Bard, L.R. Faulkner, Electrochemical Methods: Fundamentals and Applications, 2nd ed., Wiley, Weinheim, 2000. https://books.google.co.uk/books?id=kv56QgAACAAJ.

[33] K. Aoki, K. Honda, K. Tokuda, H. Matsuda, Voltammetry at microcylinder electrodes. Part I. Linear sweep voltammetry, J. Electroanal. Chem. 182 (1985) 267-279. doi:10.1016/03681874(85)87005-2.

[34] I. Streeter, N. Fietkau, J. Del Campo, R. Mas, F.X. Mũnoz, R.G. Compton, Voltammetry at 
regular microband electrode arrays: Theory and experiment, J. Phys. Chem. C. 111 (2007) 12058-12066. doi:10.1021/jp073224d.

[35] I. Streeter, R.G. Compton, Linear sweep voltammetry at randomly distributed arrays of microband electrodes, J. Phys. Chem. C. 111 (2007) 15053-15058. doi:10.1021/jp0747205.

[36] D. Li, C. Lin, C. Batchelor-McAuley, L. Chen, R.G. Compton, Tafel analysis in practice, J. Electroanal. Chem. 826 (2018) 117-124. doi:10.1016/j.jelechem.2018.08.018.

[37] E.O. Barnes, A. Fernández-La-Villa, D.F. Pozo-Ayuso, M. Castaño-Alvarez, R.G. Compton, Validating the geometry of interdigitated band electrodes: A variable scan rate study, J. Electroanal. Chem. 748 (2015) 82-90. doi:10.1016/j.jelechem.2015.04.021.

[38] T.R.L.C. Paixão, R.C. Matos, M. Bertotti, Development of a Dual-Band Amperometric Detector for Determination of Ascorbic Acid and Glucose, Electroanalysis. 15 (2003) 1884-1889. doi:10.1002/elan.200302773.

[39] E.M. Richter, J.A. Fracassi da Silva, I.G. Rolf Gutz, C.L. do Lago, L. Angnes, Disposable twin gold electrodes for amperometric detection in capillary electrophoresis, Electrophoresis. 25 (2004) 2965-2969. doi:10.1002/elps.200305960.

[40] P. Tomcik, D. Bustin, Voltammetric determination of iodide by use of an interdigitated microelectrode array, Anal. Bioanal. Chem. 371 (2001) 562-564. doi:10.1007/s002160101010.

[41] P. Tomčík, P. Jenčušová, M. Krajčíková, D. Bustin, R. Brescher, The detection of formaldehyde in textiles using interdigitated microelectrode array diffusion layer titration with electrogenerated hypobromite, Anal. Bioanal. Chem. 383 (2005) 864-868. doi:10.1007/s00216-005-0055-0.

[42] P. Tomčík, Š. Mesároš, D. Bustin, Titrations with electrogenerated hypobromite in the diffusion layer of interdigitated microelectrode array, Anal. Chim. Acta. 374 (1998) 283-289. doi:10.1016/S0003-2670(98)00398-5.

[43] T.A. Postlethwaite, J.E. Hutchison, R. Murray, B. Fosset, C. Amatore, Interdigitated Array Electrode as an Alternative to the Rotated Ring-Disk Electrode for Determination of the Reaction Products of Dioxygen Reduction, Anal. Chem. 68 (1996) 2951-2958. doi:10.1021/ac960327b.

[44] C.-N. Kuo, P.-C. Lin, F.J. Del Campo, Y.-C. Tsai, Construction of a Hydrogen Peroxide Biosensor 
on Interdigitated Microband Electrodes Fabricated by a Mix-and-Match Process, J. Electrochem. Soc. 162 (2015) B133-B137. doi:10.1149/2.0261507jes.

[45] E.O. Barnes, G.E.M. Lewis, S.E.C. Dale, F. Marken, R.G. Compton, Generator-collector double electrode systems: A review, Analyst. 137 (2012) 1068-1081. doi:10.1039/c2an16174e.

[46] R.B. Morris, D.J. Franta, H.S. White, Electrochemistry at platinum band electrodes of width approaching molecular dimensions: breakdown of transport equations at very small electrodes, J. Phys. Chem. 91 (1987) 3559-3564. doi:10.1021/j100297a019.

[47] J.L. Chang, J.M. Zen, Fabrication of disposable ultramicroelectrodes: Characterization and applications, Electrochem. Commun. 8 (2006) 571-576. doi:10.1016/j.elecom.2006.01.028.

[48] Y.H. Lanyon, D.W.M. Arrigan, Recessed nanoband electrodes fabricated by focused ion beam milling, Sensors Actuators, B Chem. 121 (2007) 341-347. doi:10.1016/j.snb.2006.11.029.

[49] C.S. Henry, Microcavities Containing Individually Addressable Recessed Microdisk and Tubular Nanoband Electrodes, J. Electrochem. Soc. 146 (1999) 3367. doi:10.1149/1.1392479.

[50] L. Angnes, E.M. Richter, M.A. Augelli, G.H. Kume, Gold electrodes from recordable CDs, Anal. Chem. 72 (2000) 5503-5506. doi:10.1021/ac000437p.

[51] P.M. Kovach, W.L. Caudill, D.G. Peters, R.M. Wightman, Faradaic electrochemistry at microcylinder, band, and tubular band electrodes, J. Electroanal. Chem. 185 (1985) 285-295. doi:10.1016/0368-1874(85)80136-2.

[52] D.M. Odell, W.J. Bowyer, Fabrication of Band Microelectrode Arrays from Metal Foil and Heat-Sealing Fluoropolymer Film, Anal. Chem. 62 (1990) 1619-1623. doi:10.1021/ac00214a016.

[53] H.A.O. Hill, N.A. Klein, I.S.M. Psalti, N.J. Walton, Enzyme Dual-Electrode for Analyte Determination, Anal. Chem. 61 (1989) 2200-2206. doi:10.1021/ac00194a017.

[54] S.L. Caston, R.L. McCarley, Characteristics of nanoscopic Au band electrodes, J. Electroanal. Chem. 529 (2002) 124-134. doi:10.1016/S0022-0728(02)00948-8.

[55] J.E. Bartelt, M.R. Deakin, C. Amatore, R.M. Wightman, Construction and Use of Paired and Triple Band Microelectrodes in Solutions of Low lonic Strength, Anal. Chem. 60 (1988) 21672169. doi:10.1021/ac00170a040.

[56] L. Xiong, D. Lowinsohn, K.R. Ward, R.G. Compton, Fabrication of disposable gold macrodisc 
and platinum microband electrodes for use in room-temperature ionic liquids, Analyst. 138 (2013) 5444-5452. doi:10.1039/c3an01092a.

[57] T.V. Shea, A.J. Bard, Digital Simulation of Homogeneous Chemical Reactions Coupled to Heterogeneous Electron Transfer and Applications at Platinum/Mica/Platinum Ultramicroband Electrodes, Anal. Chem. 59 (1987) 2101-2111. doi:10.1021/ac00144a021.

[58] M. Xu, Y. Zhang, K. Wang, J. Mao, W. Ji, W. Qiu, T. Feng, M. Zhang, L. Mao, Nanoskiving Fabrication of Size-Controlled Au Nanowire Electrodes for Electroanalysis, Analyst. 144 (2019) 2914-2921. doi:10.1039/c9an00122k.

[59] A.E.E. Owen, B.J.J. Seddon, M.J.J. Eddowes, A. Firth, H.H.J.H.J. Girault, A.E.E. Owen, H.H.J.H.J. Girault, Thin film electrode: a new method for the fabrication of submicrometer band electrodes, Electrochim. Acta. 36 (1991) 763-771. doi:10.1016/0013-4686(91)85272-9.

[60] O. Laczka, J.M. Maesa, N. Godino, J. del Campo, M. Fougt-Hansen, J.P. Kutter, D. Snakenborg, F.X. Muñoz-Pascual, E. Baldrich, Improved bacteria detection by coupling magnetoimmunocapture and amperometry at flow-channel microband electrodes, Biosens. Bioelectron. 26 (2011) 3633-3640. doi:10.1016/j.bios.2011.02.019.

[61] K. Ueno, M. Hayashida, J.Y. Ye, H. Misawa, Fabrication and electrochemical characterization of interdigitated nanoelectrode arrays, Electrochem. Commun. 7 (2005) 161-165. doi:10.1016/j.elecom.2004.12.002.

[62] A. Wahl, K. Dawson, N. Sassiat, A.J. Quinn, A. O'Riordan, Nanomolar trace metal analysis of copper at gold microband arrays, J. Phys. Conf. Ser. 307 (2011). doi:10.1088/1742$6596 / 307 / 1 / 012061$.

[63] N.J. Freeman, R. Sultana, N. Reza, H. Woodvine, J.G. Terry, A.J. Walton, C.L. Brady, I. Schmueser, A.R. Mount, Comparison of the performance of an array of nanoband electrodes with a macro electrode with similar overall area, Phys. Chem. Chem. Phys. 15 (2013) 81128118. doi:10.1039/c3cp50759a.

[64] J.G. Terry, I. Schmüser, I. Underwood, D.K. Corrigan, N.J. Freeman, A.S. Bunting, A.R. Mount, A.J. Walton, Nanoscale electrode arrays produced with microscale lithographic techniques for use in biomedical sensing applications, IET Nanobiotechnology. 7 (2013) 125-134. doi:10.1049/iet-nbt.2013.0049.

[65] I. Schmueser, A.J. Walton, J.G. Terry, H.L. Woodvine, N.J. Freeman, A.R. Mount, A systematic 
study of the influence of nanoelectrode dimensions on electrode performance and the implications for electroanalysis and sensing, Faraday Discuss. 164 (2013) 295-314. doi:10.1039/c3fd00038a.

[66] R. Sultana, N. Reza, N.J. Kay, I. Schmueser, A.J. Walton, J.G. Terry, A.R. Mount, N.J. Freeman, Practical Implications of using Nanoelectrodes for Bioanalytical Measurements, Electrochim. Acta. 126 (2014) 98-103. doi:10.1016/j.electacta.2013.12.026.

[67] O. Ordeig, N. Godino, J. Del Campo, F.X. Muñoz, F. Nikolajeff, L. Nyholm, On-chip electric field driven electrochemical detection using a poly(dimethylsiloxane) microchannel with gold microband electrodes, Anal. Chem. 80 (2008) 3622-3632. doi:10.1021/ac702570p.

[68] N. Creedon, R. Sayers, B. O'sullivan, E. Kennedy, P. Lovera, A. O'Riordan, Label-free impedimetric nanoband sensor for detection of both Bovine Viral Diarrhoea virus (BVDV) and antibody (BVDAb) in serum, (2018). doi:10.26434/chemrxiv.7326719.v1.

[69] M.P. Nagale, I. Fritsch, Individually Addressable, Submicrometer Band Electrode Arrays. 1. Fabrication from Multilayered Materials, Anal. Chem. 70 (1998) 2902-2907. doi:10.1021/ac971040x.

[70] M.P. Nagale, I. Fritsch, Individually Addressable, Submicrometer Band Electrode Arrays. 2. Electrochemical Characterization, Anal. Chem. 70 (1998) 2908-2913. doi:10.1021/ac971041p.

[71] J.A. Alden, M.A. Feldman, E. Hill, F. Prieto, M. Oyama, B.A. Coles, R.G. Compton, P.J. Dobson, P.A. Leigh, Channel Microband Electrode Arrays for Mechanistic Electrochemistry. TwoDimensional Voltammetry: Transport-Limited Currents, Anal. Chem. 70 (1998) 1707-1720. doi:10.1021/ac971248i.

[72] M. Samuelsson, M. Armgarth, C. Nylander, Microstep Electrodes: Band Ultramicroelectrodes Fabricated by Photolithography and Reactive Ion Etching, Anal. Chem. 63 (1991) 931-936. doi:10.1021/ac00009a020.

[73] N.A.M. Said, K. Twomey, V.I. Ogurtsov, D.W.M. Arrigan, G. Herzog, Fabrication and electrochemical characterization of micro- and nanoelectrode arrays for sensor applications, J. Phys. Conf. Ser. 307 (2011). doi:10.1088/1742-6596/307/1/012052.

[74] K.L. Soh, W.P. Kang, J.L. Davidson, Y.M. Wong, D.E. Cliffel, G.M. Swain, Ordered array of diamond ultramicroband electrodes for electrochemical analysis, Diam. Relat. Mater. 17 (2008) 240-246. doi:10.1016/j.diamond.2007.12.023. 
[75] F.J. Del Campo, L. Abad, X. Illa, E. Prats-Alfonso, X. Borrisé, J.M. Cirera, H.Y. Bai, Y.C. Tsai, Determination of heterogeneous electron transfer rate constants at interdigitated nanoband electrodes fabricated by an optical mix-and-match process, Sensors Actuators, B Chem. 194 (2014) 86-95. doi:10.1016/j.snb.2013.12.016.

[76] Z. Porat, J.C. Crooker, Y. Zhang, Y. Le Mest, R.W. Murray, iR UNC Advantages and Real Geometrical Dimensions of Microband Electrodes, Anal. Chem. 69 (1997) 5073-5081. doi:10.1021/ac970803d.

[77] C.A. Amatore, M.R. Deakin, M. Wightman, Electrochemical kinetics at microelectrodes Part 1. Quasi-reversible electron transfer at cylinders, J. Electroanal. Chem. 206 (1986) 23-36. doi:10.1016/0022-0728(86)90253-6.

[78] R. Lin, T.M. Lim, T. Tran, Carbon nanotube band electrodes for electrochemical sensors, Electrochem. Commun. 86 (2018) 135-139. doi:10.1016/j.elecom.2017.11.023.

[79] P.U. Prayikaputri, J. Gunlazuardi, T.A. Ivandini, Fabrication and characterization of micro-band boron-doped diamond electrode for an application in adenosine phosphates sensor, IOP Conf. Ser. Mater. Sci. Eng. 188 (2017) 12035. http://stacks.iop.org/1757$899 X / 188 / i=1 / a=012035$.

[80] P.E. Oomen, Y. Zhang, R.C. Chiechi, E. Verpoorte, K. Mathwig, Electrochemical sensing with single nanoskived gold nanowires bisecting a microchannel, Lab Chip. 18 (2018) 2913-2916. doi:10.1039/c8lc00787j.

[81] K. Dawson, J. Strutwolf, K.P. Rodgers, G. Herzog, D.W.M. Arrigan, A.J. Quinn, A. O’Riordan, Single nanoskived nanowires for electrochemical applications, Anal. Chem. 83 (2011) 55355540. doi:10.1021/ac2004086.

[82] R. Lin, T. Tran, Mass Transport Through Carbon Nanotube-Polystyrene Bundles, J. Electron. Mater. 45 (2016) 2490-2495. doi:10.1007/s11664-016-4384-x.

[83] D.H. Craston, C.P. Jones, D.E. Williams, N. El Murr, Microband electrodes fabricated by screen printing processes: Applications in electroanalysis, Talanta. 38 (1991) 17-26. doi:10.1016/0039-9140(91)80005-K.

[84] D.E. Williams, K. Ellis, A. Colville, S.J. Dennison, G. Laguillo, J. Larsen, Hydrodynamic modulation using vibrating electrodes: Application to electroanalysis, J. Electroanal. Chem. 432 (1997) 159-169. doi:10.1016/S0022-0728(97)00214-3. 
[85] T.R.L.C. Paixão, R.C. Matos, M. Bertotti, Design and characterisation of a thin-layered dualband electrochemical cell, Electrochim. Acta. 48 (2003) 691-698. doi:10.1016/S00134686(02)00738-7.

[86] T.R.L.C. Paixaõ, R.C. Matos, M. Bertotti, Diffusion layer titration of dipyrone in pharmaceuticals at a dual-band electrochemical cell, Talanta. 61 (2003) 725-732. doi:10.1016/S0039-9140(03)00334-5.

[87] P.N. Bartlett, P.R. Birkin, Enzyme Switch Responsive to Glucose, Anal. Chem. 65 (1993) 11181119. doi:10.1021/ac00056a029.

[88] H. Rajantie, D.E. Williams, Electrochemical titrations of thiosulfate, sulfite, dichromate and permanganate using dual microband electrodes, Analyst. 126 (2001) 86-90. doi:10.1039/b008582k.

[89] H. Rajantie, D.E. Williams, Potentiometric titrations using dual microband electrodes, Analyst. 126 (2001) 1882-1887. doi:10.1039/b104698p.

[90] H. Rajantie, J. Strutwolf, D.E. Williams, Theory and practice of electrochemical titrations with dual microband electrodes, J. Electroanal. Chem. 500 (2001) 108-120. doi:10.1016/S00220728(00)00426-5.

[91] M.E. Snowden, P.H. King, J.A. Covington, J. V. MacPherson, P.R. Unwin, Fabrication of versatile channel flow cells for quantitative electroanalysis using prototyping, Anal. Chem. 82 (2010) 3124-3131. doi:10.1021/ac100345v.

[92] G.D. O’Neil, S. Ahmed, K. Halloran, J.N. Janusz, A. Rodríguez, I.M. Terrero Rodríguez, Singlestep fabrication of electrochemical flow cells utilizing multi-material 3D printing, Electrochem. Commun. 99 (2019) 56-60. doi:10.1016/j.elecom.2018.12.006.

[93] M.E. Hyde, T.J. Davies, R.G. Compton, Fabrication of random assemblies of metal nanobands: A general method, Angew. Chemie - Int. Ed. 44 (2005) 6491-6496. doi:10.1002/anie.200502128.

[94] D. Bustin, Š. Mesároš, P. Tomčík, M. Rievaj, V. Tvarožek, Application of redox cycling enhanced current at an interdigitated array electrode for iron-trace determination in ultrapure spectral carbon, Anal. Chim. Acta. 305 (1995) 121-125. doi:10.1016/00032670(94)00418-L.

[95] F. Prieto, M. Oyama, B.A. Coles, J.A. Alden, R.G. Compton, S. Okazaki, Mechanistic 
Determination Using Arrays of Variable Sized Channel Microband Electrodes: The Oxidation of 2,3,7,8-Tetramethoxythianthrene in the Presence of Pyridine in Acetonitrile Solution, Electroanalysis. 10 (1998) 685-690. doi:10.1002/(SICI)1521-4109(199808)10:10<685::AIDELAN685>3.0.CO;2-B.

[96] P.J. Welford, J. Freeman, S.J. Wilkins, J.D. Wadhawan, C.E.W. Hahn, R.G. Compton, Laminated microelectrodes: A simple approach to the construction of inexpensive microelectrodes with a variety of geometries, Anal. Chem. 73 (2001) 6088-6092. doi:10.1021/ac010434s.

[97] R.G. Compton, G.G. Wildgoose, N. V. Rees, I. Streeter, R. Baron, Design, fabrication, characterisation and application of nanoelectrode arrays, Chem. Phys. Lett. 459 (2008) 1-17. doi:10.1016/j.cplett.2008.03.095.

[98] M.A. Hasnat, A.J. Gross, S.E.C. Dale, E.O. Barnes, R.G. Compton, F. Marken, A dual-plate ITOITO generator-collector microtrench sensor: Surface activation, spatial separation and suppression of irreversible oxygen and ascorbate interference, Analyst. 139 (2014) 569-575. doi:10.1039/c3an01826a.

[99] S.E.C. Dale, F. Marken, Pulse electroanalysis at gold-gold micro-trench electrodes: Chemical signal filtering, Faraday Discuss. 164 (2013) 349-359. doi:10.1039/c3fd00022b.

[100] S.E.C. Dale, A. Vuorema, M. Sillanpää, J. Weber, A.J. Wain, E.O. Barnes, R.G. Compton, F. Marken, Nano-litre proton/hydrogen titration in a dual-plate platinum-platinum generatorcollector electrode micro-trench, Electrochim. Acta. 125 (2014) 94-100. doi:10.1016/j.electacta.2014.01.043.

[101] S. Ding, C. Mosher, X.Y. Lee, S.R. Das, A.A. Cargill, X. Tang, B. Chen, E.S. McLamore, C. Gomes, J.M. Hostetter, J.C. Claussen, Rapid and Label-Free Detection of Interferon Gamma via an Electrochemical Aptasensor Comprising a Ternary Surface Monolayer on a Gold Interdigitated Electrode Array, ACS Sensors. 2 (2017) 210-217. doi:10.1021/acssensors.6b00581.

[102] A. Piper, B.M. Alston, D.J. Adams, A.R. Mount, Functionalised microscale nanoband edge electrode (MNEE) arrays: The systematic quantitative study of hydrogels grown on nanoelectrode biosensor arrays for enhanced sensing in biological media, Faraday Discuss. 210 (2018) 201-217. doi:10.1039/c8fd00063h.

[103] R. Dudeney, J.D. Newman, F. Davis, S.J. Setford, I.E. Tothill, Microband Sensor for As(III) Analysis: Reduced Matrix Interference, Electroanalysis. 29 (2017) 2332-2339. doi:10.1002/elan.201700242. 
[104] F. Wang, J. Tong, Y. Li, C. Bian, J. Sun, S. Xia, An electrochemical microsensor based on a AuNPs-modified microband array electrode for phosphate determination in fresh water samples, Sensors (Switzerland). 14 (2014) 24472-24482. doi:10.3390/s141224472.

[105] Y. Fu, C. Bian, J. Kuang, J. Wang, J. Tong, S. Xia, A palladium-tin modified microband electrode array for nitrate determination, Sensors (Switzerland). 15 (2015) 23249-23261. doi:10.3390/s150923249.

[106] S. Zhao, J. Tong, Y. Li, J. Sun, C. Bian, S. Xia, Palladium-gold modified ultramicro interdigital array electrode chip for nitrate detection in neutralwater, Micromachines. 10 (2019). doi:10.3390/mi10040223.

[107] D.R. Thvenot, K. Toth, R.A. Durst, G.S. Wilson, Electrochemical biosensors: Recommended definitions and classification (Technical Report), Pure Appl. Chem. 71 (1999) 2333-2348. doi:10.1351/pac199971122333.

[108] H.W. Jung, Y.W. Chang, G. yeon Lee, S. Cho, M.J. Kang, J.C. Pyun, A capacitive biosensor based on an interdigitated electrode with nanoislands, Anal. Chim. Acta. 844 (2014) 27-34. doi:10.1016/j.aca.2014.07.006.

[109] R. Oueslati, C. Cheng, J. Wu, J. Chen, Highly sensitive and specific on-site detection of serum cocaine by a low cost aptasensor, Biosens. Bioelectron. 108 (2018) 103-108. doi:10.1016/j.bios.2018.02.055.

[110] A.N. Sekretaryova, A. V. Volkov, I. V. Zozoulenko, A.P.F. Turner, M.Y. Vagin, M. Eriksson, Total phenol analysis of weakly supported water using a laccase-based microband biosensor, Anal. Chim. Acta. 907 (2016) 45-53. doi:10.1016/j.aca.2015.12.006.

[111] V. Chernikova, O. Yassine, O. Shekhah, M. Eddaoudi, K.N. Salama, Highly sensitive and selective SO2 MOF sensor: The integration of MFM-300 MOF as a sensitive layer on a capacitive interdigitated electrode, J. Mater. Chem. A. 6 (2018) 5550-5554. doi:10.1039/c7ta10538j.

[112] Y. Xiao, L. Huang, Q. Zhang, S. Xu, Q. Chen, W. Shi, Gravure printing of hybrid MoS2@S-rGO interdigitated electrodes for flexible microsupercapacitors, Appl. Phys. Lett. 107 (2015) 1-6. doi:10.1063/1.4926570. 


\section{For TOC only}

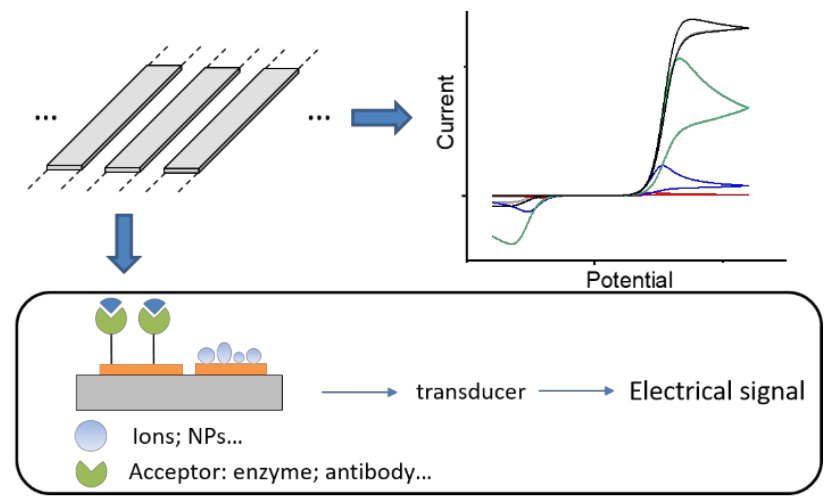

